\title{
INDIRECT AND SEMI-DIRECT AEROSOL CAMPAIGN
}

\section{The Impact of Arctic Aerosols on Clouds}

by Greg M. McFarquhar, Steven Ghan, Johannes Verlinde, Alexel Korolev, J. Walter Strapp,

Beat Schmid, Jason M. Tomlinson, Mengistu Wolde, Sarah D. Brooks, Dan Cziczo, Manvendra K. Dubey, Jiwen Fan, Connor Flynn, Ismail Gultepe, John Hubbe, Mary K. Gilles, Alexander Laskin, Paul Lawson, W. Richard Leaitch, Peter liu, Xiaohong Liu, Dan lubin, Claudio Mazzoleni, Ann-Marie Macdonald,

Ryan C. Moffet, Hugh Morrison, Mikhail Ovchinnikov, Matthew D. Shupe, David D. Turner, Shaocheng Xie, Alla Zelenyuk, Kenny Bae, Matt Freer, ${ }^{+}$and Andrew Glen

ISDAC's unique set of data about cloud and aerosol processes in Arctic mixed-phase clouds is designed to enhance predictions of impacts on the region from climate change.

D ecent studies (ACIA 2005) concluded that the Arctic is warming twice as fast as the rest of the Earth, resulting in a rapid retreat of the arctic sea ice. In September 2007, sea ice extent was the smallest since satellite observations began in 1979 (Comiso et al. 2008). The observed sea ice melting and polar amplification of the warming exceeds expectations based on simulations of the climate response to increasing greenhouse gas concentrations (Solomon et al. 2007). Although snow and ice albedo feedbacks are

likely primary drivers for the polar amplification (Vavrus 2004), other forcing and feedback mechanisms also play important roles. In particular, climate simulations suggest that cloud feedback (Vavrus 2004) and absorption by black carbon (Quinn et al. 2008) are important contributors to arctic warming. Indeed, observations show that changes in clouds may have played a significant role in the large sea ice loss during 2007 (Kay and Gettelman 2009). However, the uncertainty associated with the treatment of clouds and aerosols in climate models leads to $>$ 
large uncertainties in the prediction of arctic climate change (Inoue et al. 2006). Thus, projections from global climate models (GCMs) range from the summer sea ice vanishing within $30 \mathrm{yr}$ (Wang and Overland 2009) to the end of the twenty-first century (Boe et al. 2009), with most models significantly underestimating observed trends in arctic ice seasonal decline (Stroeve et al. 2007).

Complex interactions among clouds, aerosols, and other components of the arctic climate system must be better understood to resolve the large differences between the observations and GCM simulations of arctic climate change. Observations show that clouds have an annual-mean net warming effect on the arctic surface (Walsh and Chapman 1998). However, GCM simulations and radiative transfer calculations show that this effect is sensitive to assumed cloud properties; for instance, modifying the effective radius of water droplets by $50 \%$ can alter the surface energy budget by up to $40 \mathrm{~W} \mathrm{~m}^{-2}$ (Curry et al. 1993), and a change in effective radius of ice crystals can induce variations up to $80 \mathrm{~W} \mathrm{~m}^{-2}$ (Harrington and Olsson 2001).

Field measurements provide the basis for improved understanding and representation of arctic cloud and aerosol processes in GCMs. Data collected at the Department of Energy Atmospheric Radiation Measurement Program's ground-based facility at the North Slope of Alaska (NSA) show that mixedphase clouds, where water and ice coexist, prevail in the spring and fall (Intrieri et al. 2002). These clouds have a significant impact on the radiative budget (e.g., Dong et al. 2001) and occur in both single and multiple layers (Verlinde et al. 2007), with a typical layer structure having liquid tops and precipitating ice (Hobbs and Rangno 1998).

Arctic mixed-phase clouds can persist for days (Shupe et al. 2006). Modeling studies suggest they persist because of the balance among cloud-top radiative cooling, latent heating, ice sedimentation, and large-scale forcing (Pinto 1998; Harrington et al. 1999). This balance depends on assumptions about ice fall speeds, cloud single-scattering properties, ice nuclei (IN) concentrations, primary and secondary nucleation mechanisms, and large-scale forcing (e.g., Jiang et al. 2000). Fridlind et al. (2007) showed that the observed ambient IN were insufficient to explain observed ice crystal concentrations, and they hypothesized that the formation of IN from drop evaporation residuals and drop freezing during evaporation might explain the observations. However, because this study was based on observations acquired in pristine conditions during the Mixed-Phase Arctic Cloud Experiment (M-PACE), and because the response of clouds to increased aerosols depends on underlying surface conditions (Morrison et al. 2008), aerosol impacts on arctic clouds in a variety of surface and meteorological conditions must be quantified.

There are considerable variations in the concentrations and composition of arctic aerosols. Shaw (1982) first identified the arctic haze associated with the transport of aerosols from Europe and Asia. Aerosols are typically found in stratified layers at altitudes up to $9 \mathrm{~km}$ (Barrie 1986). A strong seasonal cycle has been observed over Barrow (Quinn et al. 2002), Alaska, with the greatest concentrations found during winter and a marked transition between March and May as the haze becomes rarer and clouds are more
AFFILIATIONS: MCFARQUHAR, BAE, AND FreER*-University of Illinois at Urbana-Champaign, Urbana, Illinois; GHAN, SCHMID, Tomlinson, Cziczo, Fan, Flynn, Hubbe, Laskin, X. Liu, Ovchinnikov, AND ZelenYuk-Pacific Northwest National Laboratory, Richland, Washington; VerLINDE-The Pennsylvania State University, University Park, Pennsylvania; Korolev, Strapp, GultePe, Lealtch, P. LiU, MACDONALD-Science and Technology Branch, Environment Canada, Downsview, Ontario, Canada; Wolde AND BRooks-National Research Council of Canada, Ottawa, Ontario, Canada; DubeY And MAZZOLENI ${ }^{+}$- Los Alamos National Laboratory, Los Alamos, New Mexico; Gilles And MoffetLawrence Berkeley National Laboratory, Berkeley, California; LAWson-Stratton Park Engineering Company, Boulder, Colorado; LUBIN-Scripps Institution of Oceanography, La Jolla, California; MORRISON-National Center for Atmospheric Research, Boulder, Colorado; SHUPE-Cooperative Institute for Research in Environmental Science, Climate Diagnostics Center, and NOAA/ ESRL, Boulder, Colorado; TURNER-University of Wisconsin-
Madison, Madison, Wisconsin; XIE-Lawrence Livermore National Laboratory, Livermore, California; GLEN-Texas A\&M University, College Station, Texas

*CURRENT AFFILIATION: European Facility for Airborne Research, Toulouse, France

+CURRENT AFFILIATION: Michigan Technological University, Houghton, Michigan

CORRESPONDING AUTHOR: Dr. Greg M. McFarquhar, 105

S. Gregory St., Dept. of Atmospheric Sciences, University of Illinois at Urbana-Champaign, Urbana, IL 6180I-3070

E-mail:mcfarq@atmos.uiuc.edu

The abstract for this article can be found in this issue, following the table of contents.

DOI:10.1175/2010BAMS2935.1

A supplement to this article is available online (10.1175/2010BAMS2935.2)

In final form 17 August 2010

(0)2011 American Meteorological Society 
frequent and thick. Prior observations also suggest that higher cloud condensation nuclei (CCN) numbers occur in winter and early spring than in summer or early autumn (Leaitch et al. 1984; Yum and Hudson 2001), and that IN occur less frequently in October (Prenni et al. 2009) than in May (Rogers et al. 2001). Seasonal and long-term variations in nuclei should produce variations in droplet and crystal concentrations. The influence of corresponding changes in cloud microphysical properties on solar radiation is known as the aerosol indirect effect on energy balance. In the arctic winter, variations in aerosol properties produce a longwave indirect effect in which higher drop numbers and smaller sizes increase the longwave emissivity of clouds (Garrett and Zhao 2006; Lubin and Vogelmann 2006).

Black carbon has been measured in aerosols at the ground in Barrow (Hansen et al. 1989; Quinn et al. 2008) and Alert (Sharma et al. 2004) and by aircraft in Svalbard, Norway (Hara et al. 2003). Even though sources of black carbon have been characterized (Stohl 2006; Shindell et al. 2008), the process of its deposition to the surface is not. Arctic climate is sensitive to black carbon because it affects snow albedo, accelerates melting (McConnell et al. 2007), and can lead to the evaporation of low-level clouds, the aerosol semidirect effect on energy balance. Shindell and Faluvegi (2009) found that up to $70 \%$ of Arctic warming since 1976 could be accounted for by increased black carbon emissions. Thus, there is a need to identify the vertical distribution, composition, and concentration of aerosols for studies of aerosol-cloud interactions.

Most prior studies of aerosol effects on clouds and radiation examined liquid clouds. Although some satellite studies have examined changes in ice crystal sizes resulting from increases in aerosols (Sherwood 2002), there are few studies of aerosol influences on mixed-phase clouds, particularly from a coordinated in situ-remote sensing perspective. Because phase affects cloud radiative properties (e.g., Sun and Shine 1994), large-eddy simulations, cloud-resolving models, and GCMs must correctly treat aerosol effects on all phases of clouds to determine radiative effects. Because Klein et al. (2009) and Morrison et al. (2009) have recently shown more sophisticated representations of cloud microphysics produce simulations more consistent with observations, there is a need for aerosol and cloud observations to develop and test model parameterizations. Prior field campaigns studying arctic clouds, such as the Surface Heat Budget of Arctic Ocean Experiment (SHEBA; Uttal et al. 2002), the First International Satellite Cloud
Climatology Project Regional Experiment Arctic Cloud Experiment (Curry et al. 2000), and M-PACE (Verlinde et al. 2007), provided some aerosol and cloud information, but more comprehensive and coordinated information on cloud and aerosol properties is needed during the early spring when aerosol concentrations are high and sunlight is available to influence the arctic energy balance, and during May when melting begins and the efficacy of the forcing is the greatest (Flanner et al. 2009).

Three coordinated field experiments conducted over Alaska during April of the International Polar Year (2008) provided such data. The Indirect and Semi-Direct Aerosol Campaign (ISDAC) is the focus of this manuscript. The Arctic Research of the Composition of the Troposphere from Aircraft and Satellites Experiment (Jacob et al. 2009) and the Aerosol, Radiation and Cloud Processes Affecting the Arctic Experiment (Warneke et al. 2009) were conducted at the same time as ISDAC and also contribute to this database.

This article provides an overview of ISDAC. The primary goal of ISDAC was to improve our knowledge on how changes in the composition and concentration of aerosols influence cloud properties and the associated radiative forcing. ISDAC, conducted in April 2008, built upon the success of M-PACE, conducted in October 2004, by allowing arctic aerosol and cloud properties to be contrasted between the relatively pristine fall and more polluted spring seasons. The National Research Council (NRC) of Canada Convair-580 flew 27 sorties (and 12 other transits and test flights), collecting data from an unprecedented 41 cloud and aerosol instruments for more than $100 \mathrm{~h}$ on 12 different days in varying aerosol, surface, and meteorological conditions. Flight plans were devised such that sampling was conducted above, below, and at varying altitudes in cloud so that the data could be used for both process-oriented and statistical analyses.

The primary science questions addressed by ISDAC are listed in Table 1 . The general theme was to provide detailed observations of aerosols and clouds. The ultimate goal of the Office of Biological and Environmental Research of the Office of Science in the Department of Energy is to deliver improved scientific data and models describing the potential response of the Earth's climate to increased greenhouse gas levels. Therefore, ISDAC was designed to gather high-quality data needed to improve the treatment of clouds and aerosols in climate models. Another important component was to provide observations and processed data for evaluating ground 
TABLE I. The primary science questions addressed during ISDAC.

How do properties of the arctic aerosol during April differ from those measured during the M-PACE in October?

To what extent do different properties of the arctic aerosol during April produce differences in the microphysical and macrophysical properties of clouds and the surface energy balance?

To what extent can cloud models and the cloud parameterizations used in climate models simulate the sensitivity of arctic clouds and the surface energy budget to the differences in aerosol between April and October?

How well can long-term surface-based measurements at the ARM Climate Research Facility (ACRF) NSA locale provide retrievals of aerosol, cloud, precipitation, and radiative heating in the Arctic?

and spaceborne remotely sensed cloud, aerosol, precipitation, and radiation profiles; these tie ISDAC to long-term observational datasets collected at the NSA site in Barrow.

GROUND NETWORK OBSERVATIONS. The NSA site, $2 \mathrm{~km}$ south of the Arctic Ocean near Barrow $\left(71^{\circ} 19^{\prime} \mathrm{N}, 156^{\circ} 37^{\prime} \mathrm{W}\right)$, has operated since 1997 . The site was established because of the rapid changes occurring in the arctic environment and the large climate sensitivity resulting from the snow/ice albedo feedback. Cloud profiles are derived primarily from a vertically pointing $35-\mathrm{GHz}$ cloud radar and a micropulse cloud lidar. In addition to cloud occurrence, profiles of cloud microphysical properties are provided through various retrieval algorithms (e.g., Shupe et al. 2005). Other instruments such as the Atmospheric Emitted Radiance Interferometer, a microwave radiometer, and a multifilter rotating shadowband radiometer are used to derive cloud properties integrated over the entire column (Turner 2005; Turner et al. 2007; Min and Harrison 1996, respectively). A total sky imager allows the determination of the fraction of the sky covered by clouds during daytime hours. Several radiometers measure upwelling and downwelling irradiances. Surface and tower meteorological instrumentation, a balloonborne sounding system, and a radar wind profiler provide profiles of temperature, dewpoint, and winds.

In addition to the permanent instrumentation at the NSA, additional instruments were deployed for ISDAC. These included a shortwave spectroradiometer operating between 350 and 2,200 $\mathrm{nm}$ for retrieving cloud optical depth $(\tau)$ and effective radius and a tandem differential mobility analyzer for measuring aerosol size distribution and hygroscopicity in the diameter range between 0.01 and $0.6 \mu \mathrm{m}$. Ice fog and precipitation characteristics were measured by a fog device, a total precipitation sensor, a precipitation-weighing sensor, and disdrometers (Gultepe et al. 2009). Table S1 (online at http://dx.doi. org/I0.II75/20IOBAMS2935.2) summarizes the operating characteristics of all ground-based instruments, and Fig. 1 shows photographs of the permanent and guest instrument facility at the Barrow NSA site.

\section{AIRCRAFT OBSERVATIONS AND OPERATIONS. The primary observation plat- form, the NRC Convair-580 (Fig. 2), was instru- mented by Environment Canada, NRC, and other ISDAC partners for the in situ measurements of clouds, aerosols, and state parameters, and for active and passive remote sensing observations}

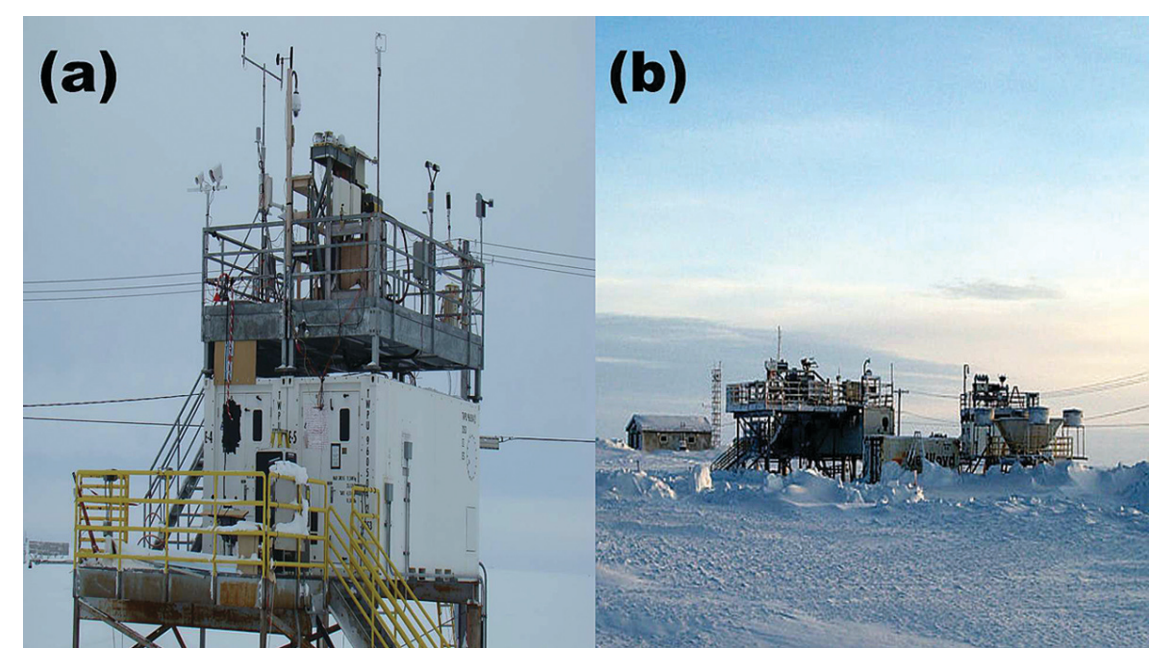

FIG. I. Photographs of (a) some of the guest instrumentation deployed at the NSA site for ISDAC (photo credit: I. Gultepe) and (b) of the permanent Barrow NSA site (courtesy: U.S. Department of Energy Atmospheric Radiation Measurement Program). Instruments and derived quantities are listed in Table SI. Guest platform's base distance above snow surface (ground) was $\mathrm{I} .2(2.5) \mathrm{m}$. The top platform is $5 \mathrm{~m}$ from the ground. There were no known sources of aerosol particles or gases upwind of the NSA site. The NSA site was $2 \mathrm{~km}$ south of the Arctic Ocean and $10 \mathrm{~km}$ east of Barrow. 


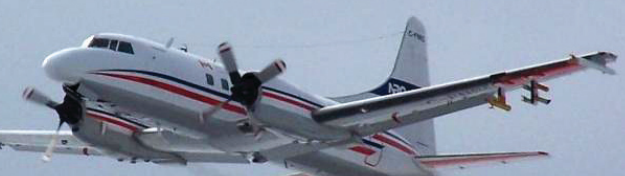

IG. 2. Photo of NRC Convair-580 taking off from Fairbanks during ISDAC. Multiple probes can be seen hanging from the wings.

(Table S2 in the online supplement at http://dx.doi. org/I0.II75/20IOBAMS2935.2). Measurements of both size-resolved and bulk cloud parameters were made from an unprecedented 20 instruments. The instruments were chosen based on experience obtained during M-PACE and other arctic experiments (e.g., Cober et al. 2001; Lawson et al. 2001). Additional instruments directly measured bulk extinction (Korolev extinctiometer) and condensed mass content [counterflow spectrometer and impactor probe (CSI) and deep-cone Nevzorov probe]. Other instruments, such as a fast forward scattering spectrometer probe (FSSP), recorded the times between arrivals of particles at the sample volumes. Instruments without shrouds or inlets [e.g., the cloud droplet probe (CDP)] were added to investigate how large crystal shattering on probe tips might amplify concentrations of particles with maximum dimensions $(D)$ between 1 and $50 \mu \mathrm{m}$. Gayet et al. (1996), Field et al. (2003), and others have suggested such shattering occurs. To quantify uncertainties in size distributions, to ensure there are no data gaps in the event of a probe malfunction, and to test the consistency of multiple probes, redundancy was critical. A two-dimensional stereographic probe (2DS; Lawson et al. 2006), an imaging probe with $10-\mu \mathrm{m}$ resolution and advanced electronics and optics, detected and imaged particles with $\sim 10<D<100 \mu \mathrm{m}$ that have been difficult to measure with standard two-dimensional cloud (2DC) or cloud imaging probes (CIP).

It was equally important to measure aerosol size, composition, concentration, morphology, and opti$\mathrm{cal}$ and nucleating properties. There were 12 instruments on the NRC Convair-580 for this purpose. A bifurcating valve was used so that most instruments drew from an aerosol inlet outside of cloud and from a counterflow virtual impactor (CVI) inlet in cloud, permitting characterization of the residual particles upon which cloud droplets and ice crystals form. The interior surface of the CVI was gold coated to identify the possible influence of crystal impaction on the measured aerosol composition (Murphy et al. 2004).
Total number concentrations were measured with condensation particle counters, and size distributions were measured using an ultra-high-sensitivity aerosol spectrometer and a Passive Cavity Aerosol Spectrometer Probe (PCASP). A continuous flow diffusion chamber (CFDC) measured IN concentration, and a Droplet Measurement Technologies CCN counter measured at two supersaturations. A time-resolved aerosol collector gathered particles for microscopic analysis (Laskin et al. 2006), and the first aircraft deployment of the Single Particle Laser Ablation Time-of-Flight Mass Spectrometer (SPLAT; Zelenyuk et al. 2009) provided single particle size and composition. All of these instruments, except the PCASP, operated behind the CVI. Aerosol optical properties, critical for knowledge of radiative effects, were measured by a particle soot absorption photometer, a nephelometer, and a three-laser photoacoustic and nephelometer (PASS-3), which was deployed on an aircraft for the first time and uses 405-, 532-, and 78-nm diode lasers aligned in an acoustic resonator to measure light absorption and total scattering. A combination of these probes allows direct determination of the wavelength dependence (Ångström exponents) of aerosol absorption, scattering, and single-scatter albedo ( $\omega_{0}$; Flowers et al. 2010).

Passive and active remote sensing observations were made by a Ka-band up- and down-looking radar and a NAWX (X-band, W-band) dual-polarization Doppler radar, as well as infrared thermometers, broadband radiometers, pyrgeometers, and an up-looking G-band passive microwave radiometer. Location and temperature observations were made, together with humidity measurements from a water vapor- $\mathrm{CO}_{2}$ instrument and chilled-mirror hygrometers. Vertical air velocities were acquired by a Rosemount gust probe. Although there were some instrumentation failures, the redundancy allowed for almost complete data coverage of important parameters for the ISDAC period.

\section{EXPERIMENT DESIGN AND EXECUTION.}

Flight plans were developed by a dedicated flight management team using output from numerical weather prediction models, satellite imagery, and real-time data from the NSA site. For a specific day, the plan was designed according to the anticipated cloud and aerosol conditions using an inventory of predetermined plans that had been separately formulated for i) missions or components of missions in the vicinity of Barrow; ii) components of flights during transits to and from Barrow; and iii) coordinated flights with the National Aeronautics and 
Space Administration (NASA) B-200 and National Oceanic and Atmospheric Administration (NOAA) P-3 aircraft in the vicinity of Barrow. During the actual mission the onboard flight scientist modified the predetermined plan based on the actual conditions, such as the levels of the cloud and aerosol layers.

Figure 3 shows all of the flight tracks of the NRC Convair-580 during ISDAC. It flew the majority of the time in the vicinity of Barrow in order to serve as a comparison with ground-based remote sensing measurements. Flight profiles consisted of i) spiral profiles over the NSA site, ii) constant-altitude legs through cloud, iii) constant-altitude legs above or below cloud, iv) missed approaches at the Barrow airport, and v) porpoising maneuvers inside the cloud (i.e., ramped ascents and descents).

For logistical reasons, the NRC Convair-580 was based out of Fairbanks, Alaska. Because 180 min were spent flying between Barrow and Fairbanks for each day of flight operations, strategies were implemented to maximize the science return of these flights. First, at least two sorties were conducted for each flight day, with the NRC Convair-580 landing at Barrow for refueling between sorties. Second, the NRC Convair-580 sampled cirrus on six transits (4, 5, 13, 19, 25, and 27 April 2008) to develop an in situ climatology of the microphysical properties of arctic cirrus, about which little is known. On days when cirrus was not present, observations characterizing tropospheric aerosols were made.

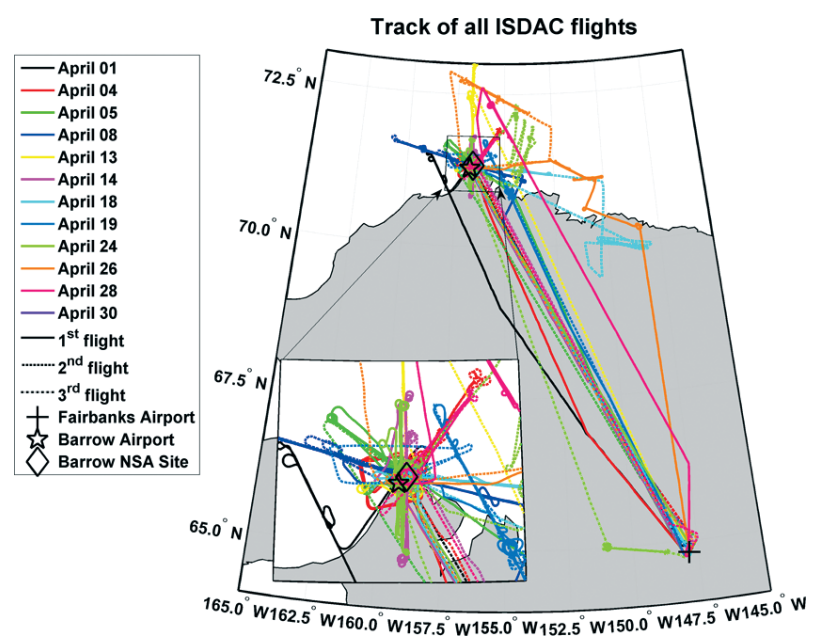

FIG. 3. Flight paths followed by the NRC Convair-580 for different days during ISDAC. Inset shows close up around Barrow where the majority of flying was conducted. Different line types represent first, second, and third flight of day (where day refers to local day of flight).
METEOROLOGICAL CONDITIONS. To understand the context of the ISDAC observations, the meteorological and surface conditions are summarized in this section. Meteorologically, during the first days of April the synoptic pattern was dominated by an upper-level trough in the Aleutian-Bering Strait area. A series of shortwave systems propagated around this longwave trough, producing precipitation through deep layers over the North Slope as a succession of frontal systems moving through the area.

On 6 April the upper-troposphere jet stream began to shift to a position well south of Alaska. A strong, deep high pressure system developed over the Yukon area, moving slowly northward across the North Pole and into northern Russia by 14 April. During this period, the upper-air synoptic pattern over Alaska was characterized by weak gradients with a high pressure system $(1,036-1,044 \mathrm{hPa})$ dominating the weather for several days. This pushed an arctic air mass across the North Slope with northeasterly to easterly flow, with temperatures averaging $-21.4^{\circ} \mathrm{C}$ between 8 and 17 April.

During this period, a single-layer stratocumulus cloud formed over Barrow on 8 April. The extensive low-level cloud formed midway between the ridgeline of the northwestward-moving high pressure system and a weakening low to its west. The cloud existed along the southern and western edge of the upperlevel ridge, reminiscent of the stratocumulus that is often observed behind a midlatitude cold front. As the synoptic system moved toward the northwest bringing the ridgeline closer to Barrow, the stratocumulus gradually thinned.

The weather regime shifted to a distinctly different pattern on 17 April when a strong upper-level low moved across the North Slope. The surface temperature increased to an average of $-8^{\circ} \mathrm{C}$ with a switch in wind direction from easterly to southwesterly. This system developed into a strong omega block with its ridgeline passing from the south to the north through central Alaska. This omega block stayed in position for 7 days, producing a succession of deep precipitating systems, each associated with shortwave troughs propagating around the ridge. During this period, a dense aerosol haze associated with Asian wild fires occurred on 19 April (Warneke et al. 2010) after the passage of a shortwave trough when the North Slope was in the warm sector behind a front. Some low-level clouds remained over Barrow. Back trajectories reveal that the air above these low-level clouds originated in central Russia.

The block finally disappeared when a strong low moving east from Kamchatka eroded the ridge on 
24 April. This low stalled in the Bering Strait where it gradually weakened even while dominating the weather over Barrow. As the low weakened Barrow became more influenced by a high pressure system over the Arctic Ocean, producing another single-layered cloud system in weak easterly flow off the ocean on 26 April. Although many other excellent cases with varying degrees of complexity were sampled during ISDAC, preliminary focus has been on the 8,19 , and 26 April cases because of their extensive sampling and relatively simple structure.

PRELIMINARY RESULTS. Initial work has concentrated on evaluating the quality of the data, and characterizing the properties required for more detailed studies of cloud-aerosol interactions. In this section, some of the observed aerosol and cloud conditions are characterized and results from preliminary scientific investigations summarized.

Ice nuclei concentrations. The CFDC measured IN concentrations over a broad range of instrumental operating conditions. While ISDAC was the first campaign for this specific instrument, comparable IN measurements have been made in the Arctic with similar instruments (Rogers et al. 2001; Prenni et al. 2009). Upstream of the CFDC, the incoming airstream passes through a cyclone impactor to prevent particles with $D>\sim 1.5 \mu \mathrm{m}$ from entering its chamber. The airstream is then exposed to the chosen operating conditions. All of the particles that have nucleated and grown to be ice crystals with $D>5 \mu \mathrm{m}$ within the chamber are counted at the exit. The IN concentrations were highly variable, ranging from less than 1 to more than $10 \mathrm{~L}^{-1}$, with isolated incidents of extremely high concentrations $\left(>100 \mathrm{~L}^{-1}\right)$.

Figure 4 shows the average concentration of IN in clear-air conditions on the ambient inlet at processing temperatures between $-10^{\circ}$ and $-30^{\circ} \mathrm{C}$ for all flights between 8 and 28 April sorted by water saturation to differentiate between heterogeneous nucleation modes. Data collected below water saturation (i.e., supersatuations SS from $-10 \%$ to $0 \%$ ) represent ice crystals formed by deposition freezing, whereas data collected above water saturation $(0 \%-10 \%$ $\mathrm{SS}_{w}$ ) include all crystals nucleated by immersion, condensation, and depositional freezing. Because of limitations in internal mixing and residence time in the chamber, the CFDC likely undercounts nucleation resulting from contact freezing. Thus, the total IN concentration reported under conditions in which contact freezing is significant may be low. Significant IN concentrations were observed below

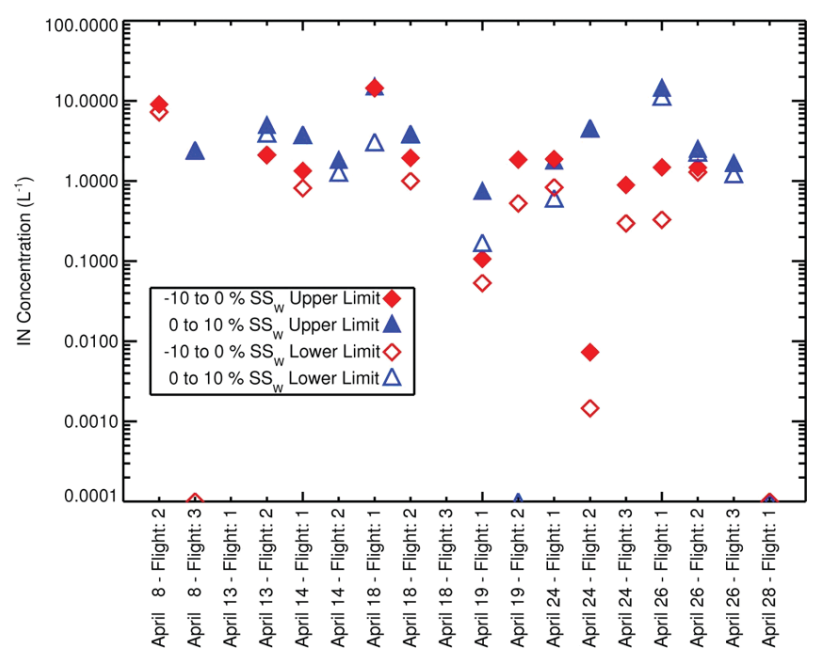

FIg. 4. Average IN concentrations measured below(solid diamonds; from $-10 \%$ to $0 \% \mathrm{SS}_{w}$ ) and abovewater saturation (triangles; from $0 \%$ to $+10 \% \mathbf{S S}_{w}$ ) as function of flight number. In addition, lower limits to the IN concentrations below- (open diamonds; from $-10 \%$ to $0 \% \mathrm{SS}_{w}$ ) and above-water saturation (triangles; from $0 \%$ to $+10 \% S_{w}$ ) are shown. Data in the figure were collected by sampling on the ambient inlet during clear-air conditions.

$\mathrm{SS}_{w}=0 \%$, indicating that depositional nucleation occurred. On all flights when data were collected both above and below $\mathrm{SS}_{w}=0 \%$, IN concentrations were higher for $\mathrm{SS}_{w}>0 \%$. However, the increase in IN with water saturation was highly variable between days, which suggests that the relative importance of the freezing mechanisms varied. At times, such as in the arctic haze on 18 April, the airborne particles were highly active as deposition nuclei. On this day, IN concentrations above water saturation were only $\sim 6 \%$ higher than those observed below water saturation.

IN concentrations in the Arctic are generally low, making accurate IN measurements a challenge. Because data collected during times when IN concentrations were below the CFDC detection threshold are not included in the averages in Fig. 4, the averages represent an upper limit to IN concentration. For comparison, during periods when the IN counts were below the threshold, the data were reprocessed assuming the IN concentration was zero. These data, representing the lower limit of the measured IN concentrations, are also shown in Fig. 4. Overall, the average IN concentrations decrease by an average of $36 \%$. In general, both the average and occasional spikes in IN concentrations observed during ISDAC are similar to previous springtime observations of IN during SHEBA. In contrast, measurements 


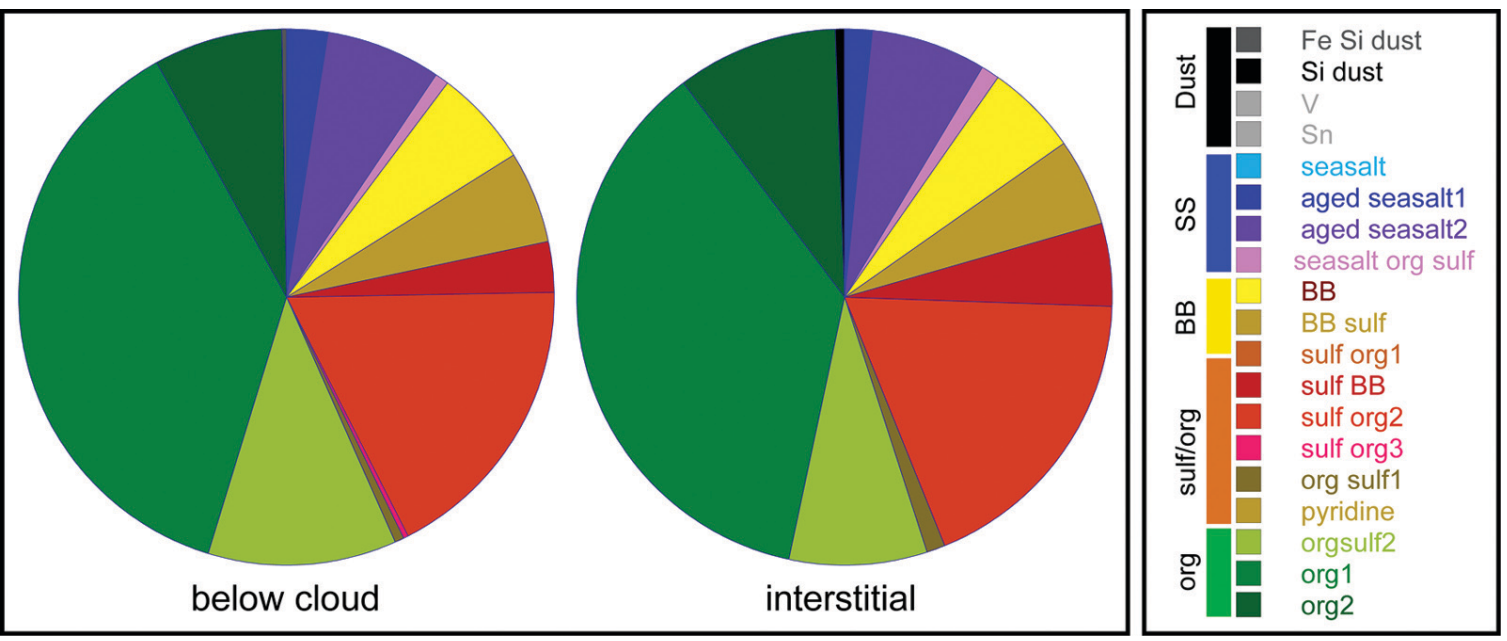

FIG. 5. Pie charts showing the compositions of (left) particles below cloud and the composition of interstitial particles in cloud that were not activated. Observations were acquired over a 19-min period on 26 Apr with interstitial particles sampled for $136 \mathrm{~s}$.

taken during M-PACE in the pristine fall season (27 September-22 October 2004) were lower $\left(\leq 1 \mathrm{~L}^{-1}\right)$ and below the CFDC's detection threshold $85 \%$ of the time (Verlinde et al. 2007). Collectively, these data suggest a strong seasonal dependence of the aerosol available to act as IN.

Aerosol composition. SPLAT measures the size and composition with 1-s resolution of individual aerosols in the $50-\mathrm{nm}$ - to $1-\mu \mathrm{m}$-diameter range as well as particle number concentrations and asphericity factors. Size distributions were acquired with between 10 - and 60-s resolution, depending on the number concentrations. During ISDAC, SPLAT measured the size of tens of millions of particles and characterized the composition of $\sim 3$ million. These data were used to extract the average aerosol density and densities of chemically resolved particle classes that were then used to obtain quantitative information on particle compositions. Particles sampled through the aerosol inlet characterize background aerosol outside of cloud and those sampled through the CVI inlet characterize particles activated as CCN and IN. By comparing the properties of CCN and IN particles to those below and above clouds, the types of particles most likely to activate can be quantified.

The SPLAT data indicate a wide range of particle compositions. Many aerosol layers had horizontal and vertical filamentous structures, in which aerosol number concentration, their size distributions, and compositions varied rapidly along the flight paths. On a number of flights, plumes containing high concentrations of transported biomass-burning particles were encountered. Analysis of a fraction of the data acquired in ice clouds shows that many IN were either metallic or composed of dust and that a significant fraction were as small as $100 \mathrm{~nm}$.

A detailed analysis of the single-layer stratocumulus cloud sampled on 26 April showed that nearly $90 \%$ of the particles were activated when this cloud formed. Figure 5 shows the individual particle compositions that were varied and included fresh and processed sea salt particles, biomass-burning particles, sulfates mixed with organics, and a large number of

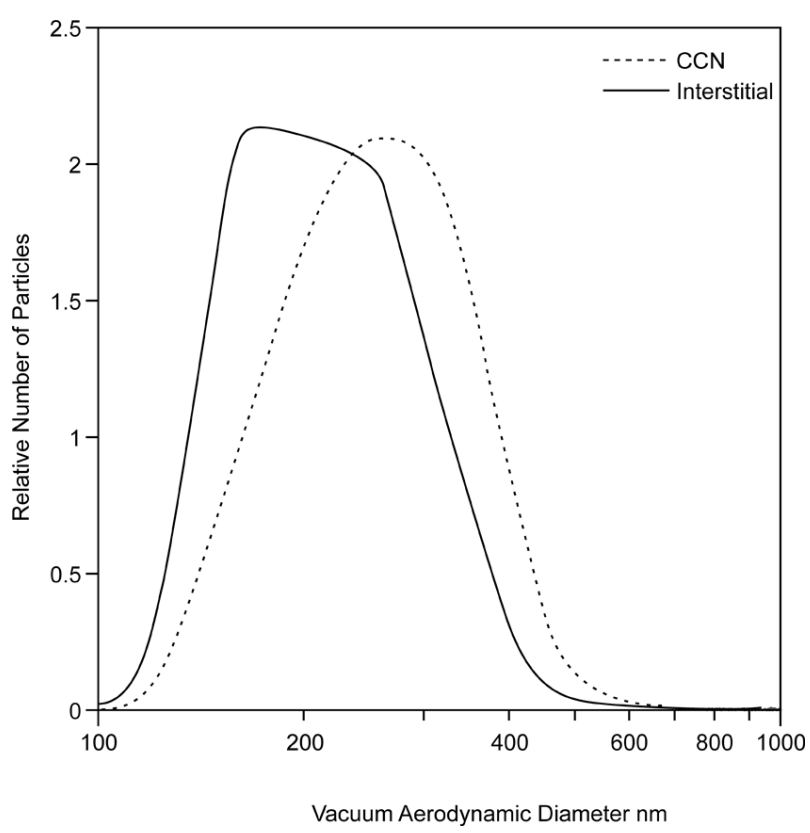

FIG. 6. The SPLAT-measured size distribution of the particles that activated to form cloud droplets (dotted) and of particles that were not activated (solid). Observations acquired on 26 Apr. 
organic particles. The comparison between the two pie charts of particles below the cloud (on left) and interstitial particles (i.e., those that were not activated; on right) shows them to be exceptionally similar, indicating that the composition of particles that acted as CCN and those that did not was nearly identical. The particle densities show that sulfate-rich particles are slightly more likely to be activated. The SPLAT size distributions in Fig. 6 show that the nonactivated particles were appreciably smaller, providing a simple explanation for the difference in CCN activity.

Aerosol optical properties. On 19 April 2008 a vast plume lofted from Siberian fires and transported over Alaska (Warnecke et al. 2009) was sampled. Large aerosol absorption indicative of absorbing carbonaceous aerosols and scattering signals was measured by PASS-3 for a substantial fraction of time during transits between Fairbanks and Barrow. The aerosol was layered with large enhancements in scattering and absorption at different altitudes. The vertical distribution of $\omega_{0}$ also showed a vertical structure indicating distinct optical properties for different layers. This information will be used to derive vertical heating rates caused by arctic aerosol that will influence both the dynamics and the clouds.

To understand the chemical origins of changes in observed optical properties the PASS-3 measurements were compared against simultaneous composition measurements made with SPLAT. Figure 7a shows that, as expected, higher fractions of black carbon derived from SPLAT correspond to lower $\omega_{0}$ at all three wavelengths. Lower $\omega_{0}$ at $405 \mathrm{~nm}$ compared to 532 and $780 \mathrm{~nm}$ appears evident where higher concentrations of biomass-burning and organic aerosols are present, indicating potential enhanced absorption by coatings and/or organic aerosols at $405 \mathrm{~nm}$ (Flowers et al. 2010). In Fig. 7b, higher light absorption, especially at 532 and $780 \mathrm{~nm}$, corresponds to higher concentrations of black carbon inferred by SPLAT observations of both soot/sulfate and biomassburning particles. The relationship between optical properties is complex and depends strongly on the 


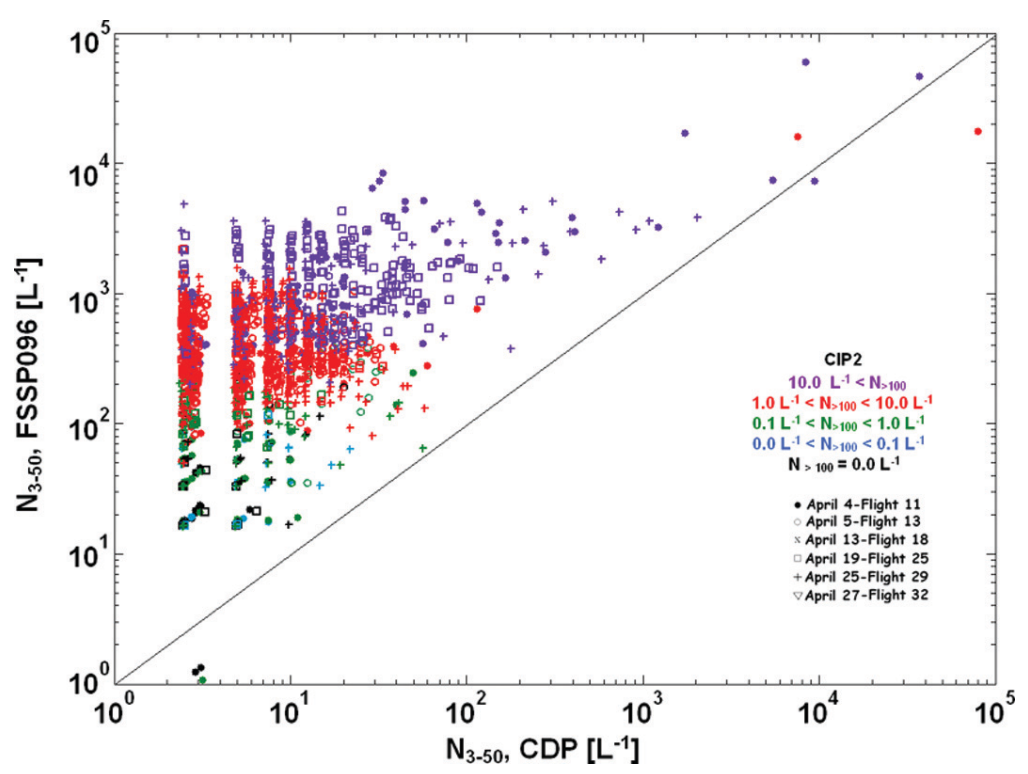

FIG. 8. $\boldsymbol{N}_{3-50, \text { FSSP }}$ as function of $\boldsymbol{N}_{3-50, \mathrm{CDP}}$ for measurements made in cirrus during transits between Fairbanks and Barrow on 4, 5, 13, 19, and $25 \mathrm{Apr}$ 2008. Different dates are indicated by different symbols. Colors indicate different concentration of particles with D > $100 \mu \mathrm{m}$ measured by the CIP2.

between $N_{3-50, \text { FSSP }}$ and $N_{3-50, \text { CDP }}$ only existed in ice-phase clouds, and not in lower-level liquid- and mixedphase clouds dominated by water. This suggests that the shattering of large ice crystals on the FSSP inlet is causing the discrepancy. McFarquhar et al. (2007a) found similar discrepancies between a cloud and aerosol spectrometer and aerosol mixing state (Jacobsen 2001). Further analysis of the data should clarify this.

Examples above illustrate a wealth of chemical, microphysical, and optical data on aged mixed organic, soot, sulfate, nitrate, and salt plumes. The preliminary results show that the aerosol chemistry and microphysics significantly affect the optical properties. The ISDAC data will be used to test physically based representations of the relationships between particle size, composition, and optical properties developed for climate models and will be especially useful for constraining models of aerosol absorption for arctic conditions.

Investigations of ice crystal shattering. To relate distributions of particle composition and size to the properties of clouds, accurate estimates of cloud microphysical properties are needed. One of the largest uncertainties in characterizing cloud microphysical properties is the uncertain contribution that small ice particles make to the total number concentration, extinction, and mass of ice- and mixed-phase clouds. Investigations are reducing these uncertainties by comparing concentrations of small particles measured during ISDAC in overlapping size ranges.

Figure 8 shows the number concentration of particles with $3<D<50 \mu \mathrm{m}$ measured by the FSSP $\left(N_{3-50, \text { FSSP }}\right)$ as a function of that measured by the CDP (hereafter $N_{3-50, \mathrm{CDP}}$ ) for observations made in cirrus between Fairbanks and Barrow. Here, $N_{3-50 \text {,FSSP }}$ is greater by one to two orders of magnitude than $N_{3-50, \mathrm{CDP}}$, and $N_{3-50, \mathrm{FSSP}} / N_{3-50, \mathrm{CDP}}$ increases with the concentrations of particles with $D>100 \mu \mathrm{m}$ measured by CIP number 2 (CIP2). This systematic offset
CDP in tropical cirrus.

Processing of the $10-\mu \mathrm{m}$-resolution 2DS data eliminates many shattered particles using an interarrival time measurement, because the shattered fragments often pass through the sample volume in clusters. Thus, a comparison of the concentrations of particles with $10<D<50 \mu \mathrm{m}$ from the 2DS (hereafter $N_{10-50,2 \mathrm{DS}}$ ) against those derived from the FSSP $\left(N_{10-50, \text { FSSP }}\right)$ offers another perspective for in-

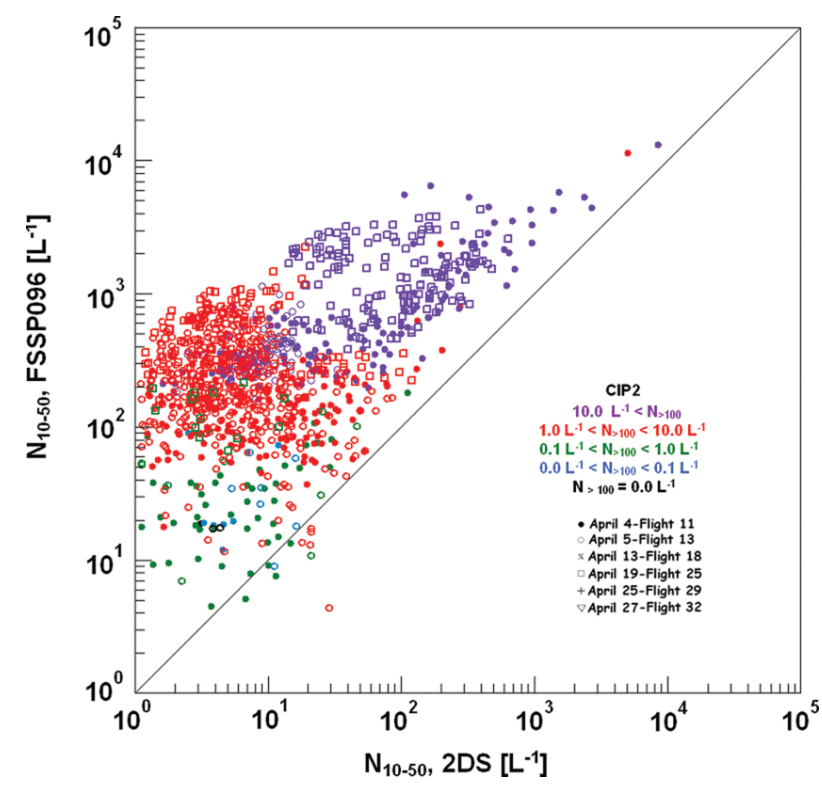

FIG. 9. $N_{10-50,2 D S}$ as function of $N_{10-50, F S S P}$ for measurements made in cirrus during transits between Fairbanks and Barrow on 4, 5, 13, 19, and 25 Apr 2008. Different dates are indicated by different symbols. Colors indicate different concentration of particles with $D>100 \mu \mathrm{m}$ measured by the CIP2. 
vestigating shattering on the FSSP. Figure 9 shows that $N_{10-50, \text { FSSP }}$ is systematically higher than $N_{10-50,2 \mathrm{DS}}$. Because the ratio of the number concentration measured by the FSSP to that measured by the 2DS (shattered particles removed) is dependent on the large ice crystal concentrations, this reconfirms earlier studies, which showed measurements of small ice crystals that may be affected by the shattering of large ice crystals on inlets and tips.

Examination of longevity of mixed-phase clouds. Flight profiles executed through single-layer stratocumulus on 8 and 26 April 2008 are ideal for investigating cloud-aerosol interactions and factors responsible for the longevity of arctic mixed-phase clouds because the single layer allows the interactions of aerosols and clouds to be isolated without complications of interactions between multiple cloud layers. On the second sortie on 8 April (Fig. 10), the NRC Convair-580 took off from Barrow and immediately ascended through cloud and above, flying between 1.0 and $1.3 \mathrm{~km}$ high on a $180-\mathrm{km}$ leg relative to the ground, sampling the aerosol above cloud west-northwest of Barrow. Thereafter it descended below cloud to $0.5 \mathrm{~km}$ and briefly sampled residuals of precipitation particles from the CVI inlet. After briefly circling because of air traffic, it flew a constant-altitude leg in cloud at $0.8 \mathrm{~km}$, a leg below cloud at $0.5-0.6 \mathrm{~km}$ sampling from the aerosol inlet, and then another leg in cloud at altitudes between 0.8 and $1.0 \mathrm{~km}$; these legs were approximately parallel to each other. The NRC Convair-580 then performed a spiral descent and ascent between 0.5 and $1.0 \mathrm{~km}$ over the NSA site. The sortie was completed with a leg measuring aerosols above cloud ascending from 1.0 to $1.2 \mathrm{~km}$, a leg porpoising from cloud top $(0.9-1.2 \mathrm{~km})$ to cloud base $(0.5 \mathrm{~km})$, a leg through the cloud $(0.7-0.8 \mathrm{~km})$, and a leg below cloud $(0.5 \mathrm{~km})$.

Although Fig. 11 shows that the mixed-phase clouds observed on 8 April appear visually smooth, observations with the NRC X-band radar in Fig. 12 show small-scale structure and inhomogeneities in the cloud microphysical characteristics. In particular, Doppler velocities $\left(V_{d}\right)$ corrected for aircraft motion suggest regions of positive $V_{d}$ (ascent) of about 1-2 $\mathrm{m} \mathrm{s}^{-1}$ (blue color) in close proximity to regions of nega- tive $V_{d}$ (descent) of 1-4 $\mathrm{m} \mathrm{s}^{-1}$. The close coupling of these downward and upward $V_{d}$ is a first indicator of the role of dynamics, mixing, and turbulence in these cloud systems (e.g., Shupe et al. 2008).

Figure 13 represents a two-dimensional view of the horizontal and vertical variations in bulk microphysical characteristics derived from probes on the ramped ascents and descents of the NRC Convair-580

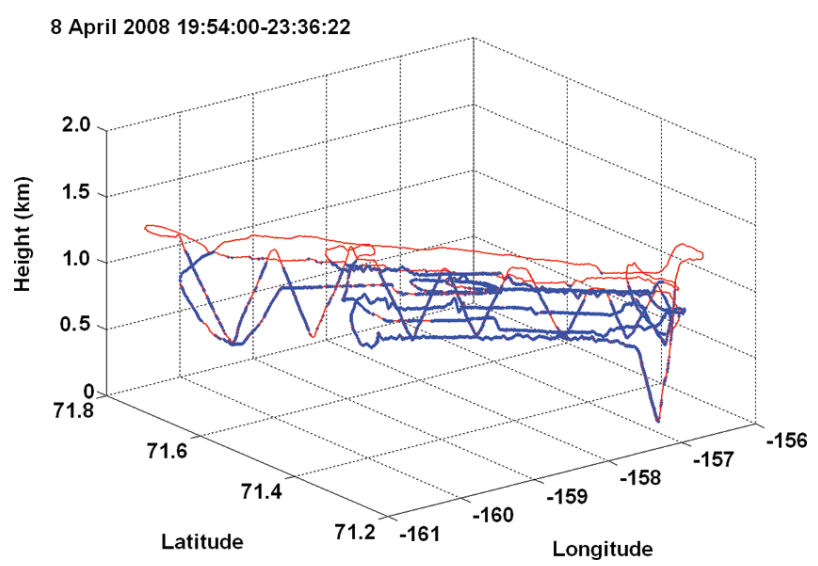

FIG. 10. Flight track flown by NRC Convair-580 on second flight of 8 Apr. Constant-altitude flight legs flown above, below, and within cloud, together with ramped ascents and descents through cloud and spirals over NSA site are depicted. Blue represents locations where clouds were sampled, with cloud identified as locations where 10 -s-averaged CSI total water content $>0.001 \mathrm{~g} \mathrm{~m}^{-3}$. Convair-580 on 8 Apr 2008. Glory and shadow of aircraft are seen in photo. Photo taken by A. Korolev when NRC Convair-580 was executing flight leg above stratocumulus.

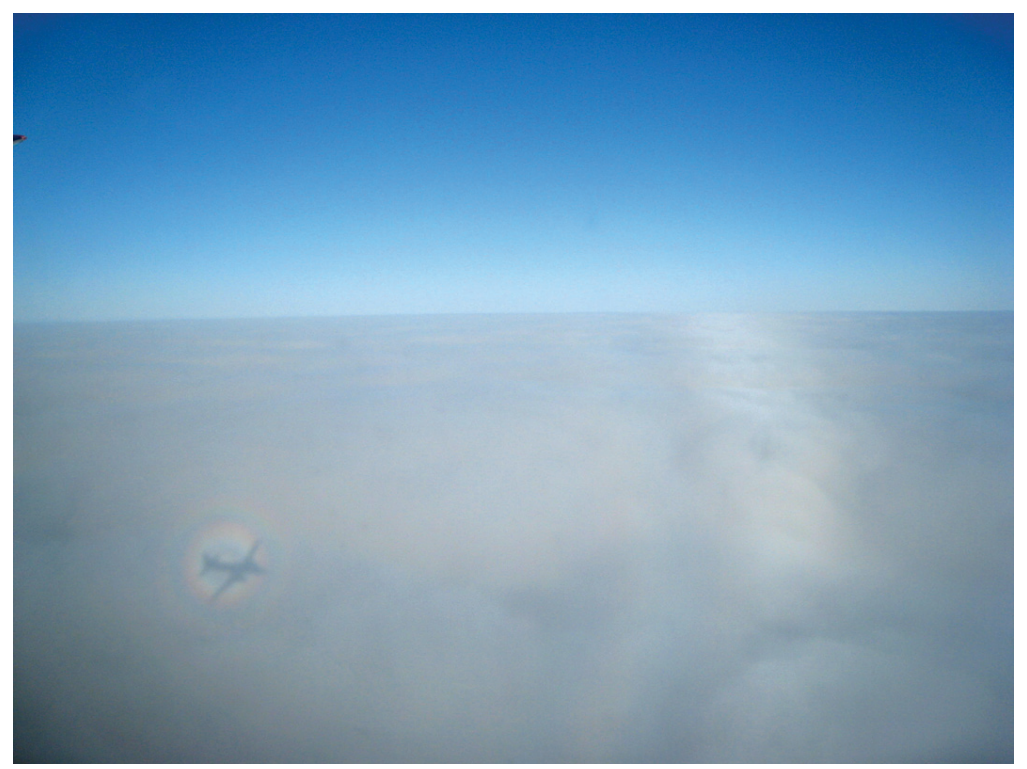



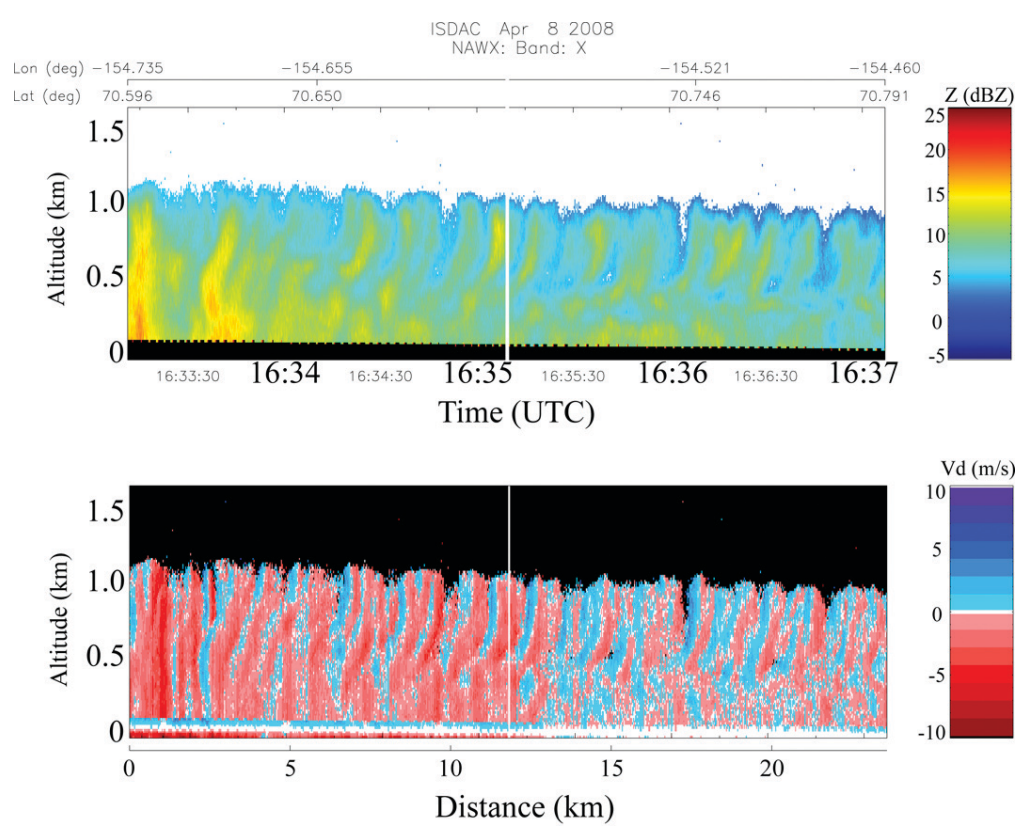

FIG. I2. Cross section of reflectivity $(Z)$ and Doppler velocity $\left(V_{d}\right)$, with negative values indicating downward motion, measured by NRC $X$-band radar during a near-constant-altitude leg flight above singlelayer stratocumulus on $8 \mathrm{Apr}$. Contribution of aircraft to $V_{d}$ has been removed (ground is shown as white $\sim 0 \mathrm{~m} \mathrm{~s}^{-1}$ in $V_{d}$ image).

during its $180-\mathrm{km}$-long porpoising leg perpendicular to the wind direction through the cloud. The blue shading represents the location of the liquid cloud layer identified from the cloud probes. The following noteworthy features are evident in Fig. 13: 1) there is a strong temperature inversion of about $5^{\circ} \mathrm{C}$ capping the vertical growth of the cloud; 2) the sum of the concentrations derived from the FSSP and the PCASP is close to constant throughout and below cloud; 3) there is a gradual increase in LWC with height in the cloud; and 4) although there is a reduction in the concentration and IWC from larger-sized ice crystals observed by the 2DP near the cloud top, there is otherwise no large variation with height. Inspection of ice crystal images indicated that both large and small crystals occurred throughout cloud. The presence of small particles everywhere indicates that either nucleation was occurring throughout cloud or that there was significant vertical mixing. Although the microphysical inhomogeneities and the variability in cloud height for the single-layer stratocumulus sampled on 26 April were not as large (figure not shown), similar trends were noted. McFarquhar et al. (2007b) also noted similar trends in the single-layer stratocumulus sampled during M-PACE.

The combination of the inhomogeneities in the radar data and the nearly constant ice profiles through cloud indicates vertical mixing driven by dynamics or turbulence. Preliminary simulations using the models of Korolev and Isaac (2003) and Korolev and Field (2008) show that harmonic oscillations consistent with the observed velocity fields provide the conditions necessary for the indefinitely long maintenance of these mixed-phase clouds when no precipitation reaches the surface. Like most stratocumulus this cloud layer was maintained by cloud-top radiative cooling that drove these circulations. In addition to dynamical factors, the longevity of low-level arctic stratus depends on cloud microphysics, which helps control liquid-to-ice conversion and precipitation rates. Because microphysics process rates are not measured directly, they can be tested via the numerical modeling used to quantify these processes. Figure 14 shows one example where a highresolution model with size-resolved liquid and ice microphysics (Fan et al. 2009) simulated a quasi-steady-state mixedphase single-layer stratocumulus with a structure similar to that observed on 26 April. The agreement between the observations and models is obtained when ice nucleation is constrained with observed ice concentrations of about $4 \mathrm{~L}^{-1}$. Ice nucleation is needed to maintain the ISDAC mixed-phase clouds that are driven only by cloud-top radiative cooling because of the Bergeron-Findeisen process.

An earlier study over the ice-free ocean during M-PACE demonstrated that although many models could maintain a mixed-phase cloud, they underpredicted liquid water path and overpredicted precipitation (Klein et al. 2009). These model shortcomings are expected to be exposed more fully in ISDAC case studies when the ocean is mostly ice covered, surface sensible and latent heat fluxes are substantially reduced, and boundary layer clouds are driven primarily by cloud-top radiative cooling, making them sensitive to the presence of liquid. This stronger coupling between dynamics and microphysics in springtime arctic clouds thus provides a more stringent test for constraining key model parameters.

Aerosol effects on cloud. One science question addressed by ISDAC is the influence of aerosol on cloud microphysical properties. This influence is illustrated in Fig. 15, which compares mean number con- 
centrations of cloud droplets and subcloud aerosol particles larger than $0.1 \mu \mathrm{m}$ on six different flights. The droplet and aerosol number concentrations are highly correlated, with some evidence of nonlinear dependence, possibly resulting from suppressed supersaturation at higher aerosol concentrations.
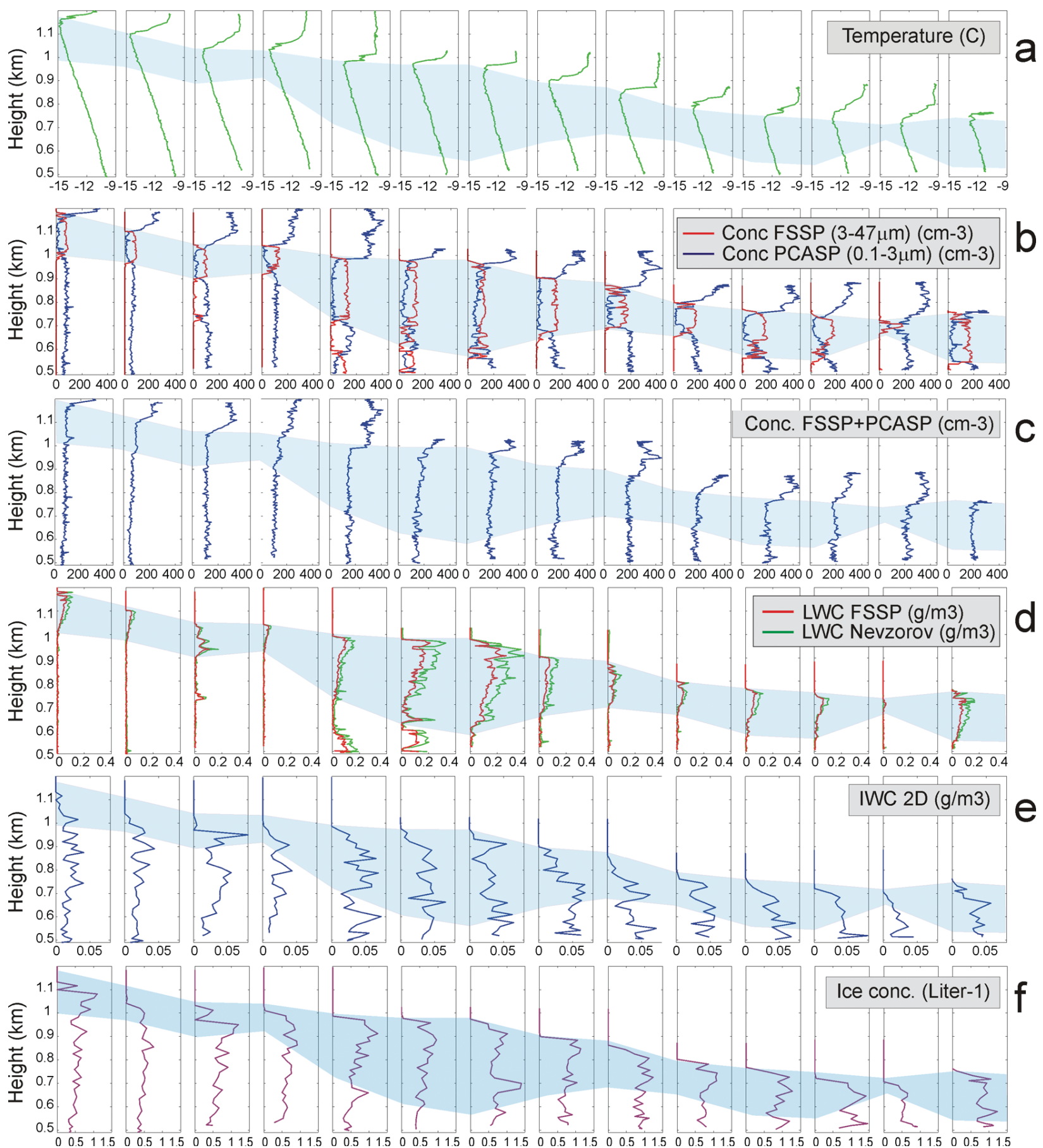

Fig. 13. Vertical profile of (a) temperature, (b) cloud droplet number concentration from FSSP $\left(\boldsymbol{N}_{d}\right)$ and aerosol concentration from PCASP $\left(\boldsymbol{N}_{a}\right)$, (c) $\boldsymbol{N}_{d}+\boldsymbol{N}_{a}$, (d) liquid water content derived from FSSP size distribution and directly measured by Nevzorov probe, (e) ice water content derived from size distribution measured by 2DP, and (f) ice crystal concentration derived from 2DP. Each vertical profile was obtained during a single ramped ascent or descent during the leg when NRC Convair-580 porpoised from cloud top to bottom during sortie 16 on 8 Apr 2008. Blue shading, based on analysis of individual profiles, represents location of liquid cloud layer on each profile. 


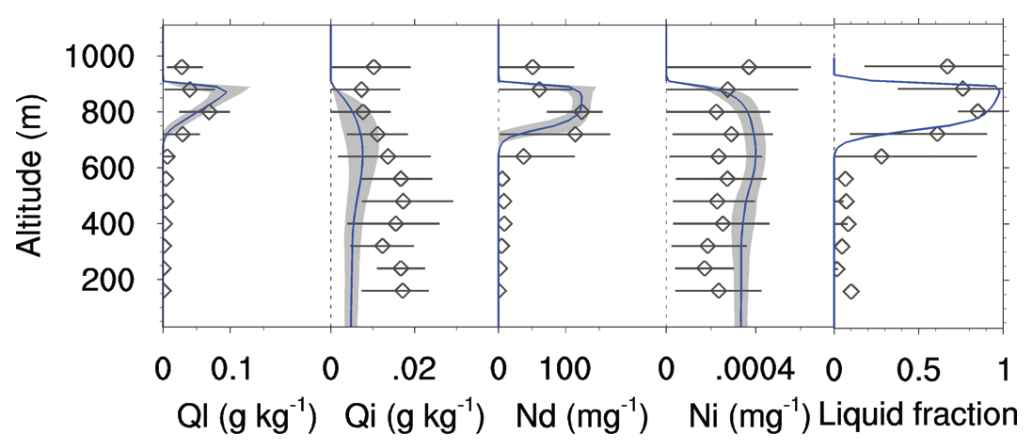

FIG. I4. Model predicted (lines) and observed (diamonds) mean vertical profiles of mixed-phase cloud parameters (liquid QI and ice Qi mass mixing ratios, droplet $\mathrm{Nd}$ and ice particle $\mathrm{Ni}$ number mixing ratios, and liquid water condensate fraction) for sortie 3 I on $26 \mathrm{Apr}$ 2008. Shaded area and horizontal lines indicate 15-85 percentile ranges for simulated and measured parameters, respectively. For $\mathbf{N d}$,

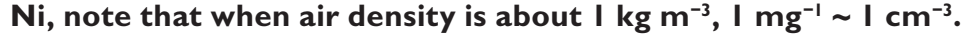

Cloud-resolving single-column regional and global models are being applied to the ISDAC data to separate aerosol effects from meteorological and surface effects. To separate the influence of surface boundary and aerosol conditions, the following series of four simulations are planned: M-PACE aerosol and surface boundary conditions, ISDAC aerosol and surface boundary conditions, M-PACE aerosol and ISDAC surface boundary conditions, and ISDAC aerosol and M-PACE surface boundary conditions. The surface boundary conditions are different for ISDAC and M-PACE because more extensive ocean water

This is qualitatively consistent with expectations and has been previously observed (Leaitch et al. 1986, 1996). However, further work is needed to combine these data with updraft velocity and aerosol size and composition data to quantitatively test understanding of aerosol effects on droplet formation. Previous efforts in this area (e.g., Conant et al. 2004; Meskhidze et al. 2005; Fountoukis et al. 2007) had, and to some extent used, bulk composition data, but did not have single-particle composition data to test the dependence of this agreement on single-particle composition.

The influence of aerosols on clouds is further illustrated in Fig. 16 where the frequency distribution of cloud droplet number concentrations measured by the FSSP for flights in single-layer stratocumulus on 8 and 26 April are shown. The concentrations are greater for the larger aerosol concentrations observed on 26 April compared to those observed on 8 April, consistent with past studies of arctic clouds (Gultepe and Isaac 2002). It should also be noted that both the aerosol and droplet concentrations varied by up to a factor of 2 between the east and west side of the legs flown on 26 April. Future work will explore the dependence of droplet size, ice crystal concentration, and ice particle size on aerosol concentration stratifying the extensive ISDAC data according to location in cloud, meteorological forcing, and surface conditions. is present in fall compared to spring.

Surface spectroradiometer data. Figure 17 illustrates how surface spectroradiometer data can diagnose the impact of cloud phase on the radiation budget. In Fig. 17a, three downwelling flux spectra are shown, each obtained $2.5 \mathrm{~h}$ into the first and second flights of 24 April and the second flight of 26 April. Preliminary analysis of in situ cloud microphysical data indicate that the three clouds sampled during these flights were composed of primarily ice (from the first flight on 24 April), a roughly equal mixture of water and ice (from the second flight on 24 April), and primarily liquid (from the second flight on 26 April).

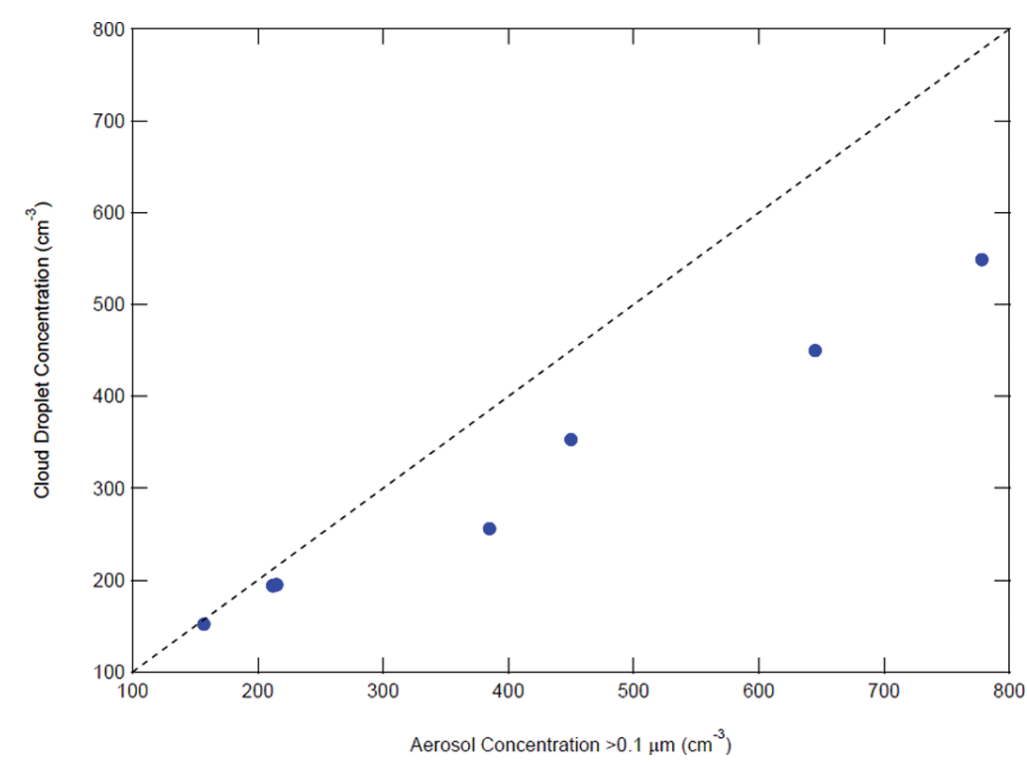

FIG. I5. Mean concentrations of cloud droplets and subcloud aerosol particles larger than $\mathbf{0 . I} \mu \mathrm{m}$ on six different flights during ISDAC. 


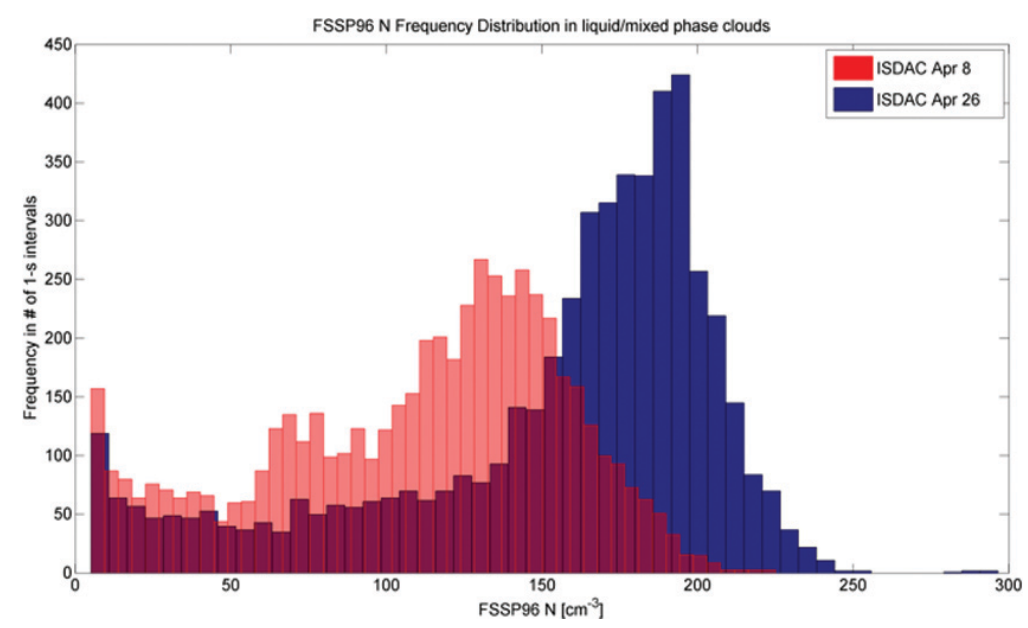

FIG. I6. Frequency distribution of number concentration measured by FSSP in liquid- and mixed-phase clouds for single-layer stratocumulus sampled on 8 and 26 Apr 2008. Each measurement represents a I-s average or approximately $120 \mathrm{~m}$ of track length.

Noticeable contrasts appear in both the spectral dependence and total flux in the $1.6-\mu \mathrm{m}$ window. In Fig. 17b, a time series is plotted for each flight of the ratio of the flux in the $1.6-\mu \mathrm{m}$ window to the total broadband flux. At fixed total cloud optical depth and for the solar zenith angle range considered, these differences in this flux ratio correspond to differences of 5-10 $\mathrm{W} \mathrm{m}^{-2}$ between ice- and liquid-dominated cloud microphysics. Hence, the ISDAC data directly reveal the influence of cloud phase on surface shortwave radiation.

SUMMARY AND FUTURE WORK. The data collected by 41 instruments on the NRC Convair-580 during ISDAC constitute the most complete airborne dataset on aerosol microphysical and radiative properties and on arctic boundary layer and cirrus microphysical properties ever collected over the North Slope of Alaska. This paper described the science questions that motivated ISDAC and some preliminary findings. The preliminary analysis presented here has also shown the importance of considering dynamical, mixing, and turbulent processes when examining aerosol indirect and semidirect effects on clouds. Most ISDAC data are available from the ARM

FIG. I7. (a) Downwelling surface spectral flux obtained from the ASD spectroradiometer at NSA under the first and second flights of the NRC Convair-580 on $24 \mathrm{Apr}$ and under the first flight on $26 \mathrm{Apr}$. The spectra were obtained approximately $2.5 \mathrm{~h}$ into each flight. (b) For the duration of these three flights, the ratio of the surface flux in the $1.6-\mu \mathrm{m}$ window to the broadband flux is in $\mathbf{5 - m i n}$ intervals. data archive (online at www.archive. arm.gov/), and hence are open to additional investigations from the scientific community.

In addition to fundamental studies of cloud and aerosol interactions and the modeling studies described above, applications summarized in Table S3 in the online supplement (at http://dx.doi. org/I0.II75/20IOBAMS2935.2) are being explored. For each application, ISDAC data are input to a model, retrieval, or statement of mass balance, and other ISDAC data are compared with the model output, retrieval, or mass balance. For example, cloud water closure provides a consistency test for the bulk and size-resolved

measurements.

During the next few years the ISDAC data will also be used to i) test the current understanding of droplet and crystal nucleation, ii) improve the understanding of aerosol effects on the life cycle and radiative

\section{Downwelling Shortwave Surface Flux}

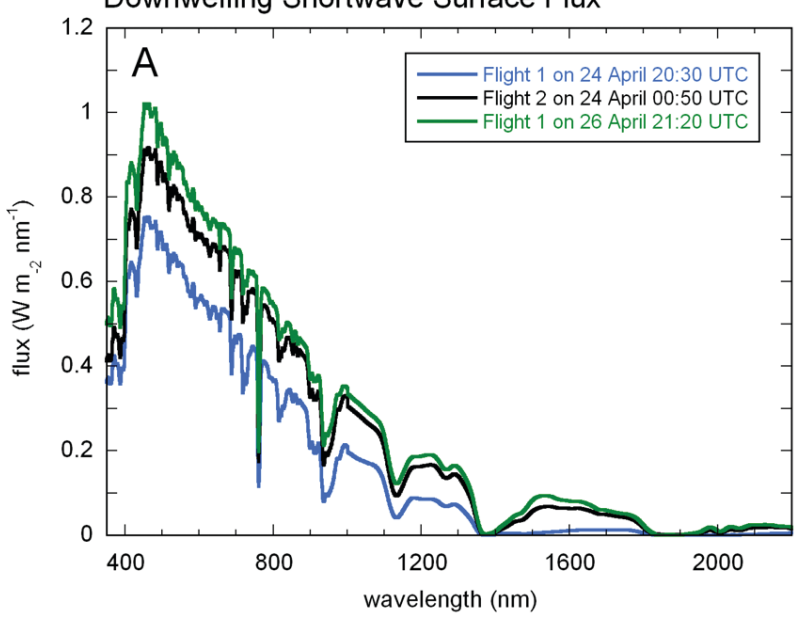

Ratio 1.6-micron Window to Broadband Flux

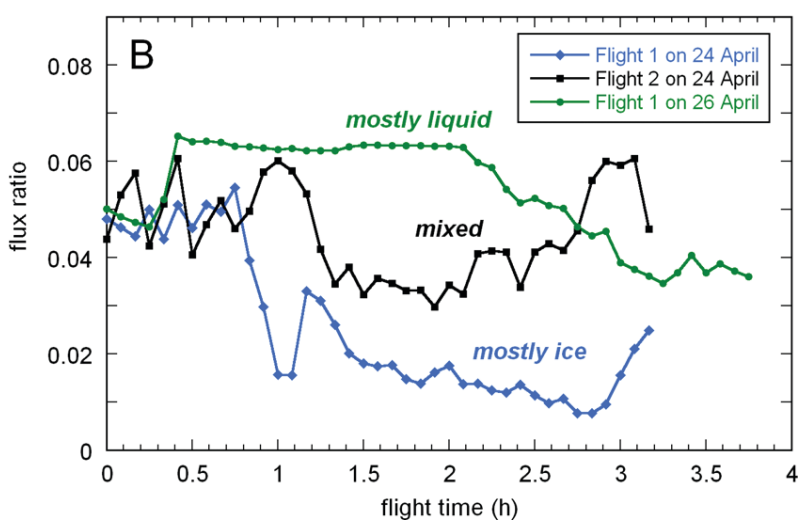


properties of mixed-phase clouds, iii) evaluate and improve the representation of mixed- and ice-phase cloud processes in a variety of cloud models, iv) test the impact of isolated processes, such as droplet nucleation, on the modeled fields, and v) test and improve remote sensing retrievals of cloud and aerosol properties from the surface and from space so that the ISDAC observations can be extended to longer time periods. Both the spiral profiles over the NSA site and some CloudSat and/or Cloud-Aerosol Lidar and Infrared Pathfinder Satellite Observations (CALIPSO) underpass flights are available for testing the retrievals. The results for the ISDAC period, when aerosol concentrations were relatively high, will be contrasted with those for the more pristine M-PACE period to assess the ability of cloud models to simulate the differences. These evaluations will guide improvements in the cloud models for the purpose of improving simulations of clouds and aerosols across the Arctic Basin. Ultimately these improvements will be used to explain the role of clouds and aerosols in the loss of arctic sea ice and improve reliability of projections of future changes in arctic climate.

ACKNOWLEDGMENTS. ISDAC was supported by the U.S. Department of Energy (DOE) Atmospheric Radiation Measurement (ARM) Program Climate Research Facility, the DOE Atmospheric Sciences Program, the National Research Council of Canada, and Environment Canada. We are indebted to the many scientists and staff who participated in ISDAC, without whose efforts this work would have been possible. Mohammed Wasey and Rob Reed provided technical support for the instrumentation on the NRC Convair-580. The assistance of Robert Jackson in preparing the manuscript was appreciated. Data were obtained from the ARM program archive, sponsored by DOE, Office of Science, Office of Biological and Environmental Research Environmental Science Division. This work was sponsored by Grants DE-FG02-02ER63337, DE-FG02-07ER64378, DE-FG02-06ER64167, and DE-FG02-09ER64770 as part of ARM. The Pacific Northwest National Laboratory is operated for DOE by Battelle Memorial Institute under Contract DE-AC06-76RLO1830. LANL acknowledges ongoing support from ASR for PASS-3 capability and the OBER-RCI project for analysis of data.

\section{REFERENCES}

ACIA, 2005: ACIA scientific report. Cambridge University Press, 1042 pp. [Available online at www.acia.uaf. edu/pages/scientific.html.]

Barrie, L. A., 1986: Arctic air pollution: An overview of current knowledge. Atmos. Environ., 20, 643-663.
Boe, J., A. Hall, and X. Qu, 2009: September sea-ice cover in the Arctic projected to vanish 2100. Nat. Geosci., 2, 341-343, doi:10.1038/ngeo467.

Cober, S. G., G. A. Isaac, A. V. Korolev, and J. W. Strapp, 2001: Assessing cloud-phase conditions. J. Appl. Meteor., 40, 1967-1983.

Comiso, J. C., C. L. Parkinson, R. Gersten, and L. Stock, 2008: Accelerated decline in the arctic sea ice cover. Geophys. Res. Lett., 35, L01703, doi:10.1029/2007GL031972.

Conant, W. C., and Coauthors, 2004: Aerosol-cloud drop concentration closure in warm cumulus. J. Geophys. Res., 109, D13204, doi:10.1029/2003JD004324.

Curry, J. A., J. Schramm, and E. E. Ebert, 1993: Impact of clouds on the surface radiation budget of the Arctic Ocean. Meteor. Atmos. Phys., 57, 197-217.

- , and Coauthors, 2000: FIRE Arctic Clouds Experiment. Bull. Amer. Meteor. Soc., 81, 5-30.

Dong, X., G. G. Mace, P. Minnis, and D. F. Young, 2001: Arctic stratus cloud properties and their effect on the surface radiation budget: Selected cases from FIRE ACE. J. Geophys. Res., 106, 15 297-15 312.

Fan, J., M. Ovtchinnikov, J. M. Comstock, S. A. McFarlane, and A. Khain, 2009: Ice formation in Arctic mixed-phase clouds: Insights from a 3-D cloud-resolving model with size-resolved aerosol and cloud microphysics. J. Geophys. Res., 114, D04205, doi:10.1029/2008JD010782.

Field, P. R., R. Wood, P. R. A. Brown, P. H. Kaye, E. Hirst, R. Greenaway, and J. A. Smith, 2003: Ice particle interarrival times measured with a fast FSSP. J. Atmos. Oceanic Technol., 20, 249-261.

Flanner, M. G., C. S. Zender, P. G. Hess, N. Mahowald, T. H. Painter, V. Ramanathan, and P. J. Rasch, 2009: Springtime warming and reduced snow cover from carbonaceous particles. Atmos. Chem. Phys., 9, 2481-2497.

Flowers, B., M. K. Dubey, C. Mazzoleni, E. A. Stone, J. J. Schauer, and S.-W. Kim, and S. C. Yoon 2010: Optical-chemical-microphysical relationships and closure studies for mixed carbonaceous aerosols observed at Jeju Island; 3-laser photoacoustic spectrometer, particle sizing, and filter analysis. Atmos. Chem. Phys., 10, 10 387-10 398.

Fountoukis, C., and Coauthors, 2007: Aerosol-cloud drop concentration closure for clouds sampled during the International Consortium for Atmospheric Research on Transport and Transformation 2004 campaign. J. Geophys. Res., 112, D10S30, doi:10.1029/2006JD007272.

Fridlind, A. M., A. S. Ackerman, G. McFarquhar, G. Zhang, M. R. Poellot, P. J. DeMott, A. J. Prenni, and A. J. Heymsfield, 2007: Ice properties of single-layer 
stratocumulus during the Mixed-Phase Arctic Cloud Experiment (M-PACE): 2. Model results. J. Geophys. Res., 112, D24202, doi:10.1029/2007JD008646.

Garrett, T. J., and C. Zhao, 2006: Increased Arctic cloud long wave emissivity associated with pollution from mid-latitudes. Nature, 440, 787-789.

Gayet, J. G., G. Febvre, and H. Larsen, 1996: The reliability of the PMS FSSP in the presence of small ice crystals. J. Atmos. Oceanic Technol., 13, 1300-1310.

Gultepe, I., and G. A. Isaac, 2002: Effects of air mass origin on Arctic cloud microphysical parameters for April 1998 during FIRE.ACE. J. Geophy. Res., 107, 8029, doi:10.1029/2000JC000440.

— Modeling (FRAM) field project. Bull. Amer. Meteor. Soc., 90, 341-359.

Hansen, A. D. A., T. J. Conway, L. P. Strele, B. A. Bodhaine, K. W. Thoning, P. Tans, and T. Novakov, 1989: Correlations among combustion effluent species at Barrow, Alaska: Aerosol black carbon, carbon dioxide, and methane. J. Atmos. Chem., 9, 283-299.

Hara, K., S. Yamagata, T. Yamanouchi, K. Sato, A. Herber, Y. Iwasaka, M. Nagatani, and H. Nakata, 2003: Mixing states of individual aerosol particles in spring Arctic troposphere during ASTAR 2000 campaign. J. Geophys. Res., 108, 4209, doi:10.1029/2002JD002513.

Harrington, J. Y., and P. Q. Olsson, 2001: On the potential influence of ice nuclei on surface-forced marine stratocumulus cloud dynamics. J. Geophys. Res., 106, 27 473-27 484.

—, T. Reisin, W. R. Cotton, and S. M. Kreidenweis, 1999: Cloud resolving simulations of Arctic stratus. Part II: Transition-season clouds. Atmos. Res., 51, 45-75.

Hobbs, P. V., and A. L. Rangno, 1998: Microstructures of low and middle-level clouds over the Beaufort Sea. Quart. J. Roy. Meteor. Soc., 124, 2035-2071.

Inoue, J., J. Liu, J. O. Pinto, and J. A. Curry, 2006: Intercomparison of arctic regional climate models: Modeling clouds and radiation for SHEBA in May 1998. J. Climate, 19, 4167-4178.

Intrieri, J. M., M. D. Shupe, T. Uttal, and B. J. McCarty, 2002: An annual cycle of Arctic cloud characteristics observed by radar and lidar at SHEBA. J. Geophys. Res., 107, 8030, doi:10.1029/2000JC000423.

Jacob, D. J., and Coauthors, 2009: The ARCTAS aircraft mission: Design and execution. Atmos. Chem. Phys. Discuss., 9, 17 073-17 123.

Jacobsen, M. Z., 2001: Strong radiative heating due to the mixing state of black carbon. Nature, 409, 695-697.

Jiang, H., W. R. Cotton, J. O. Pinto, J. A. Curry, and M. J. Weissbluth, 2000: Cloud resolving simulations of mixed-phase arctic stratus observed during base: Sensitivity to concentration of ice crystals and largescale heat and moisture advection. J. Atmos. Sci., 57, 2105-2117.

Kay, J. E., and A. Gettelman, 2009: Cloud influence on and response to seasonal Arctic sea ice loss. J. Geophys. Res., 114, D18204, doi:10.1029/2009JD011773.

Klein, S. A., and Coauthors, 2009: Intercomparison of model simulations of mixed-phase clouds observed during the ARM Mixed-Phase Arctic Cloud Experiment. Part I: Single layer cloud. Quart. J. Roy. Meteor. Soc., 135, 979-1002.

Korolev, A. V., and G. A. Isaac, 2003: Phase transformation of mixed-phase clouds. Quart. J. Roy. Meteor. Soc., 129, 19-38.

— mixed-phase clouds: Theoretical considerations. J. Atmos. Sci., 65, 66-86.

Laskin, A., J. P. Cowin, and M. J. Iedema, 2006: Analysis of individual environmental particles using modern methods of electron microscopy and x-ray microanalysis. J. Electron Spectrosc. Relat. Phenom., 150, 260-274.

Lawson, R., B. A. Baker, C. G. Schmitt, and T. L. Jensen, 2001: An overview of microphysical properties of Arctic clouds observed in May and July 1998 during FIRE ACE. J. Geophys. Res., 106, 14 989-15 014.

—, D. O'Connor, P. Zmarzly, K. Weaver, B. A. Baker, Q. Mo, and H. Jonsson, 2006: The 2D-S (stereo) probe: Design and preliminary tests of a new airborne, high-speed, high-resolution particle imaging probe. J. Atmos. Oceanic Technol., 23, 1462-1477.

Leaitch, W. R., R. M. Hoff, S. Melnichuk, and W. Hogan, 1984: Some chemical and physical properties of the arctic winter aerosol in northeastern Canada. J. Climate Appl. Meteor., 23, 916-928.

—, J. W. Strapp, G. A. Isaac, and J. G. Hudson, 1986: Cloud droplet nucleation and cloud scavenging of aerosol sulphate in polluted atmospheres. Tellus, 38B, 328-344.

_ vations in marine stratus during 1993 NARE: Factors controlling cloud droplet number concentrations. J. Geophys. Res., 101, 29 123-29 135.

Lubin, D., and A. M. Vogelmann, 2006: A climatologically significant aerosol longwave indirect effect in the Arctic. Nature, 439, 453-456.

McConnell, J. R., and Coauthors, 2007: 20th-century industrial black carbon emissions altered Arctic climate forcing. Science, 317, 1381-1384.

McFarquhar, G. M., J. Um, M. Freer, D. Baumgardner, G. L. Kok, and G. Mace, 2007a: Importance of small 
ice crystals to cirrus properties: Observations from the Tropical Western Pacific International Cloud Experiment (TWP-ICE). Geophys. Res. Lett., 34, L13803, doi:10.1029/2007GL029865.

—, G. Zhang, M. R. Poellot, G. L. Kok, R. McCoy, T. Tooman, and A. J. Heymsfield, 2007b: Ice properties of single-layer stratocumulus during the Mixed-Phase Arctic Cloud Experiment. Part I: Observations. J. Geophys. Res., 112, D24201, doi:10.1029/2007JD008633.

Meskhidze, N., A. Nenes, W. C. Conant, and J. H. Seinfeld, 2005: Evaluation of a new cloud droplet activation parameterization with in situ data from CRYSTAL-FACE and CSTRIPE. J. Geophys. Res., 110, D16202, doi:10.1029/2004JD005703.

Min, Q., and L. C. Harrison, 1996: Cloud properties derived from surface MFRSR measurements and comparison with goes results at the ARM SGP site. Geophys. Res. Lett., 23, 1641-1644.

Morrison, H., J. O. Pinto, J. A. Curry, and G. M. McFarquhar, 2008: Sensitivity of modeled arctic mixed-phase stratocumulus to cloud condensation and ice nuclei over regionally varying surface conditions. J. Geophys. Res., 113, D05203, doi:10.1029/2007JD008729.

_ _ and Coauthors, 2009: Intercomparison of model simulations of mixed-phase clouds observed during the ARM Mixed-Phase Arctic Cloud Experiment. Part II: Multi-layered cloud. Quart. J. Roy. Meteor. Soc., 135, 1003-1019.

Murphy, D. M., D. J. Cziczo, P. K. Hudson, D. S. Thomson, J. C. Wilson, T. Kojima, and P. R. Buseck, 2004: Particle generation and resuspension in aircraft inlets when flying in clouds. Aerosol Sci. Technol., 38, 400-408.

Pinto, J. O., 1998: Autumnal mixed-phased cloudy boundary layers in the Arctic. J. Atmos. Sci., 55, 2016-2038.

Prenni, A. J., P. J. DeMott, D. C. Rogers, S. M. Kreidenweis, G. M. McFarquhar, G. Zhang, and M. R. Poellot, 2009: Ice nuclei characteristics from M-PACE and their relation to ice formation in clouds. Tellus, 61B, 436-448.

Quinn, P. K., T. L. Miller, T. S. Bates, J. A. Ogren, E. Andrews, and G. E. Shaw, 2002: A 3-year record of simultaneously measured aerosol chemical and optical properties at Barrow, Alaska. J. Geophys. Res., 107, 4130, doi:10.1029/2001JD001248.

— and Coauthors, 2008: Short-lived pollutants in the arctic: Their climate impact and possible mitigation strategies. Atmos. Chem. Phys., 8, 1723-1735.

Rogers, D. C., P. J. DeMott, and S. M. Kreidenweis, 2001: Airborne measurements of tropospheric ice- nucleating aerosol particles in the arctic spring. $J$. Geophys. Res., 106, 15 053-15 063.

Sharma, S., D. Lavoué, H. Cachier, L. A. Barrie, and S. L. Gong, 2004: Long-term trends of the black carbon concentrations in the Canadian Arctic. J. Geophys. Res., 109, D15203, doi:10.1029/2003JD004331.

Shaw, G. E., 1982: Atmospheric turbidity in the polar regions. J. Appl. Meteor., 21, 1080-1088.

Sherwood, S., 2002: Aerosols and ice particle size in tropical cumulonimbus. J. Climate, 15, 1051-1063.

Shindell, D., and G. Faluvegi, 2009: Climate response to regional radiative forcing during the twentieth century. Nat. Geosci., 2, 294-300, doi:10.1038/ NGEO473.

—-, and Coauthors, 2008: A multi-model assessment of pollution transport to the Arctic. Atmos. Chem. Phys., 8, 5353-5372.

Shupe, M. D., T. Uttal, and S. Y. Matrosov, 2005: Arctic cloud microphysics retrievals from surface-based remote sensors at SHEBA. J. Appl. Meteor., 44, 1544-1562.

—, S. Y. Matrosov, and T. Uttal, 2006: Arctic mixedphase cloud properties derived from surface-based sensors at SHEBA. J. Atmos. Sci., 63, 697-811.

— , P. Kollias, P. O. G. Persson, and G. M. McFarquhar, 2008: Vertical motions in arctic stratiform mixedphase clouds. J. Atmos. Sci., 65, 1304-1322.

Solomon, S., D. Qin, M. Manning, Z. Chen, M. Marquis, K. B. Averyt, M. Tignor, and H. L. Miller, Eds., 2007: Climate Change 2007: The Physical Science Basis. Cambridge University Press, 996 pp.

Stohl, A., 2006: Characteristics of atmospheric transport into the Arctic troposphere. J. Geophys. Res., 111, D11306, doi:10.1029/2005JD006888.

Stroeve, J., M. M. Holland, W. Meier, T. Scambos, and M. Serreze, 2007: Arctic sea ice decline: Faster than forecast. Geophys. Res. Lett., 34, L09501, doi:10.1029/2007GL029703.

Sun, Z., and K. P. Shine, 1994: Studies of the radiative properties of ice and mixed-phase clouds. Quart. J. Roy. Meteor. Soc., 120, 111-137.

Turner, D. D., 2005: Arctic mixed-phase cloud properties from AERI lidar observations: Algorithm and results from SHEBA. J. Appl. Meteor., 44, 427-444.

—, S. A. Clough, J. C. Liljegren, E. E. Clothiaux, K. Cady-Pereira, and K. L. Gaustad, 2007: Retrieving liquid water path and precipitable water vapor from Atmospheric Radiation Measurement (ARM) microwave radiometers. IEEE Trans. Geosci. Remote Sens., 45, 3680-3690, doi:10.1109/TGRS.2007.903703.

Uttal, T., and Coauthors, 2002: The surface heat budget of the Arctic Ocean. Bull. Amer. Meteor. Soc., 83, 255-275. 
Vavrus, S., 2004: The impact of cloud feedbacks on arctic climate under greenhouse forcing. J. Climate, 17, 603-615.

Verlinde, J., and Coauthors, 2007: The Mixed-Phase Arctic Cloud Experiment. Bull. Amer. Meteor. Soc., 88, 205-221.

Walsh, J. E., and W. L. Chapman, 1998: Arctic cloudradiation-temperature associations in observational data and atmospheric reanalyses. J. Climate, 11, 3030-3045.

Wang, M., and J. E. Overland, 2009: A sea ice free summer Arctic within 30 years? Geophys. Res. Lett., 36, L07502, doi:10.1029/2009GL037820.

Warneke, C., and Coauthors, 2009: Biomass burning in Siberia and Kazakhstan as an important source for haze over the Alaskan Arctic in April 2008. Geophys. Res. Lett., 36, L02813, doi:10.1029/2008GL036194.

— , and Coauthors, 2010: An important contribution to springtime Arctic aerosol from biomass burning in Russia. Geophys. Res. Lett., 37, L01801, doi:10.1029/2009GL041816.

Yum, S. S., and J. G. Hudson, 2001: Vertical distributions of cloud condensation nuclei spectra over the springtime Arctic Ocean. J. Geophys. Res., 106, 15 045-15 052.

Zelenyuk, A., J. Yang, D. Imre, and E. Choi, 2009: SPLAT II: An aircraft compatible, ultra-sensitive, high precision instrument for in-situ characterization of the size and composition of fine and ultrafine particles. Aerosol Sci. Technol., 43, 411-424.

\section{AMS Bestseller!}

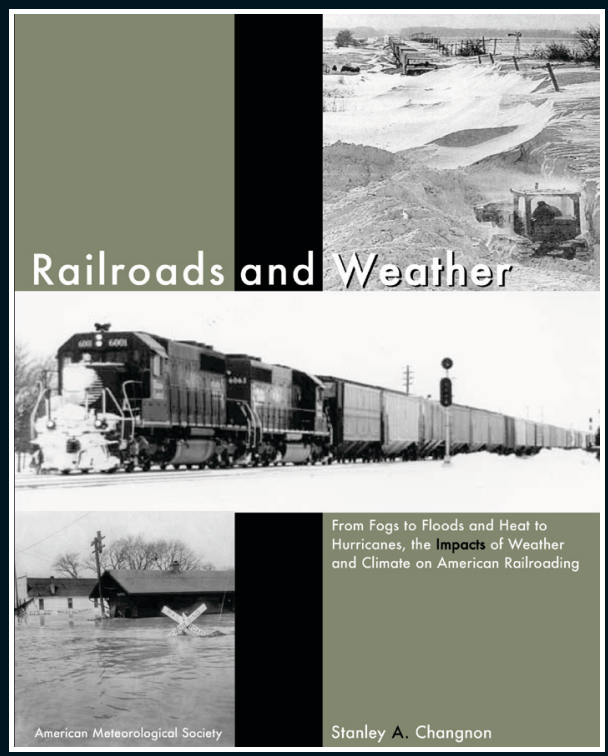

By Stanley A. Changnon $\odot 2006$

136 pp., hardbound, AMS order code: RIrds

\$24.95 member; \$29.95 non-member

ISBN 10: 1-878220-73-X

ISBN 13: 978-1-878330-73-8

\section{Railroads and Weather:}

From Fogs to Floods and Heat to Hurricanes, the Impacts of Weather and Climate on American Railroading

- More than 120 photographs and charts

- The most damaging storms of the last century

- Railroad response to Katrina

"Railroads and Weather is a must read for meteorologists wanting to understand the impact of their products on the rail community...as well as railroad operations personnel, and history buffs who just love trains."

-Richard A. Wagoner, National Center for Atmospheric Research

\section{Order online at www.ametsoc.org/amsbookstore}

or call 617-226-3998. Send prepaid orders, using

the form in the back of this issue, to the American

Meteorological Society: AMS Order Dept., 45 Beacon

www.ametsoc.org Street, Boston, MA 02108-3693 


\section{AMERICAN METEOROLOGICAL SOCIETY}

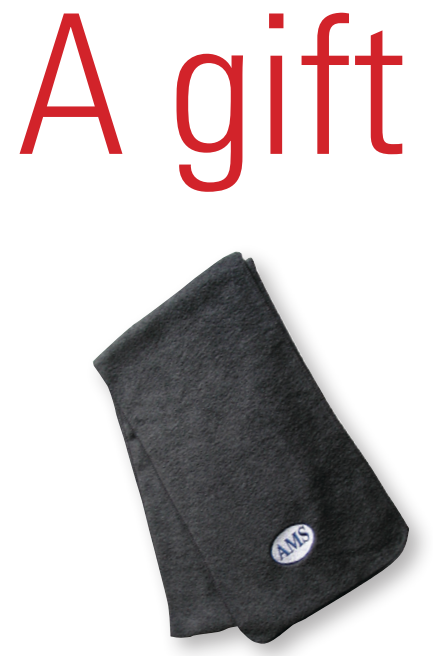

Fleece Scarf

$\$ 17$

COLOR: Charcoal with AMS emblem

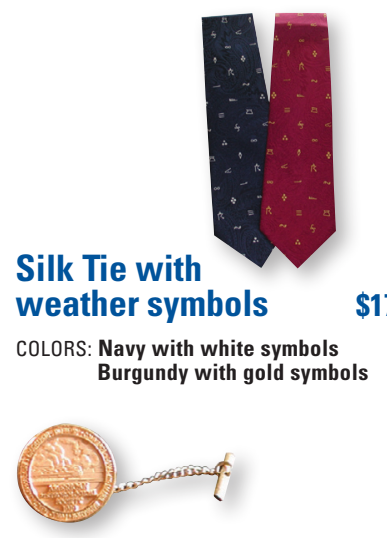

Tie Tack

COLOR: Gold

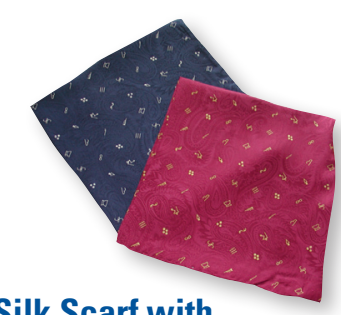

Silk Scarf with weather symbols

$\$ 17$

COLORS: Navy with white symbols Burgundy with gold symbols

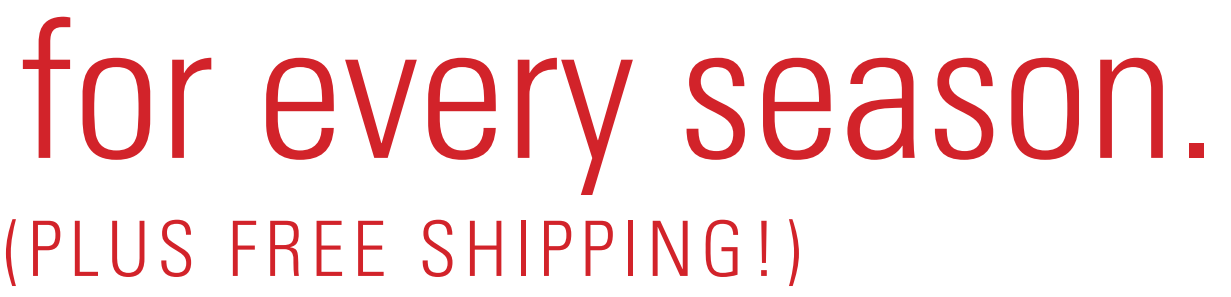

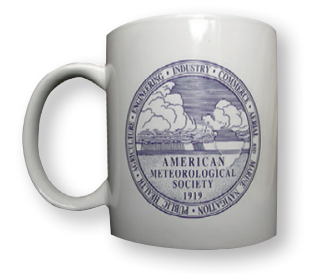

Ceramic Mug

COLORS: Navy with white AMS seal White with navy AMS seal

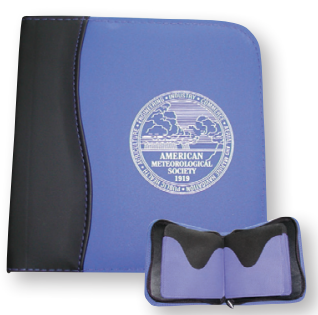

12 Pocket CD Case

$\$ 9$

COLOR: Blue with white AMS seal

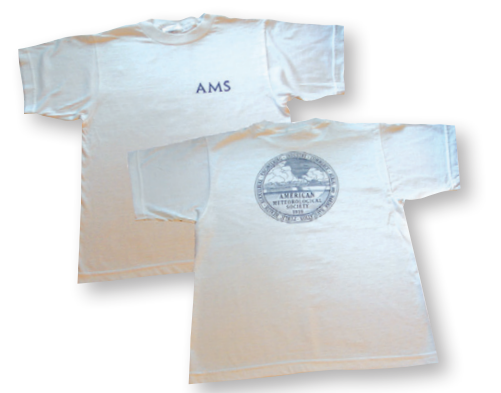

\section{Cotton T-Shirt}

Adult: $S, M, L, X L, X X L$

Child: $S, M, L$

$\$ 12$

COLORS: Navy with white AMS seal White with navy AMS seal

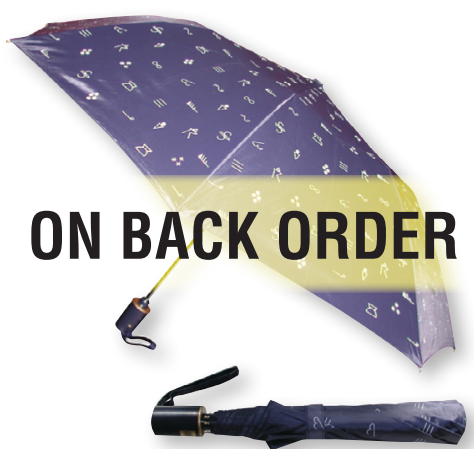

Umbrella with weather symbols

$\$ 14$

COLOR: Navy with white symbols

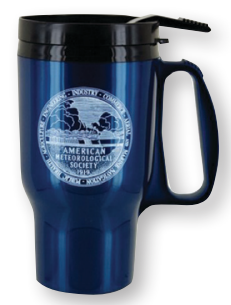

Travel Mug

$\$ 8$

COLOR: Blue with white AMS seal

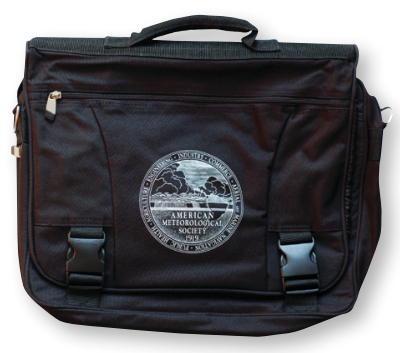

\section{Soft Briefcase}

$\$ 27$

COLOR: Black with white AMS seal DIMENSIONS: 16"L, 12.5"H, 3.75"W (expands to $5 "$ ")

ORDER TODAYI Prepay by check/money order, Visa, MC, or AMEX CALL 617-226-3998 FAX 617-742-8718 MAIL AMS, 45 Beacon Street, Boston, MA 02108-3693

FOR MORE GIFT IDEAS check out the new AMS Online Bookstore (weather books, biographies, histories, monographs and more) at www.ametsoc.org/amsbookstore.

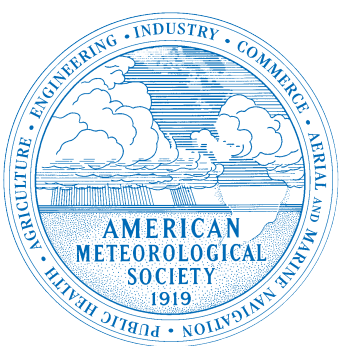

